\title{
Genetic variation of $\gamma$-tocopherol methyltransferase gene contributes to elevated $\alpha$-tocopherol content in soybean seeds
}

\author{
Maria S Dwiyanti, Tetsuya Yamada*, Masako Sato, Jun Abe and Keisuke Kitamura
}

\begin{abstract}
Background: Improvement of $\alpha$-tocopherol content is an important breeding aim to increase the nutritional value of crops. Several efforts have been conducted to improve the $\alpha$-tocopherol content in soybean [Glycine max (L.) Merr.] through transgenic technology by overexpressing genes related to $\alpha$-tocopherol biosynthesis or through changes to crop management practices. Varieties with high $\alpha$-tocopherol content have been identified in soybean germplasms. The heritability of this trait has been characterized in a cross between high $\alpha$-tocopherol variety Keszthelyi Aproszemu Sarga (KAS) and low $\alpha$-tocopherol variety Ichihime. In this study, the genetic mechanism of the high $\alpha$-tocopherol content trait of KAS was elucidated.

Results: Through QTL analysis and fine mapping in populations from a cross between KAS and a Japanese variety Ichihime, we identified $\gamma$-TMT3, which encodes $\gamma$-tocopherol methyltransferase, as a candidate gene responsible for high $\alpha$-tocopherol concentration in KAS. Several nucleotide polymorphisms including two nonsynonymous mutations were found in the coding region of $\gamma$-TMT3 between Ichihime and KAS, but none of which was responsible for the difference in $\alpha$-tocopherol concentration. Therefore, we focused on transcriptional regulation of $\gamma$-TMT3 in developing seeds and leaves. An $F_{5}$ line that was heterozygous for the region containing $\gamma$-TMT3 was self-pollinated. From among the progeny, plants that were homozygous at the $\gamma$-TMT3 locus were chosen for further evaluation. The expression level of $\gamma$-TMT3 was higher both in developing seeds and leaves of plants homozygous for the $\gamma$-TMT3 allele from KAS. The higher expression level was closely correlated with high $\alpha$ tocopherol content in developing seeds. We generated transgenic Arabidopsis plants harboring GUS gene under the control of $\gamma$-TMT3 promoter from KAS or Ichihime. The GUS activity assay showed that the activity of $\gamma$-TMT3 promoter from KAS was higher than that of Ichihime.

Conclusions: The genetic variation in $\gamma$-TMT3, which plays a major role in determining $\alpha$-tocopherol concentration, provides significant information about the regulation of tocopherol biosynthesis in soybean seeds. This knowledge will help breeding programs to develop new soybean varieties with high $\alpha$-tocopherol content.
\end{abstract}

\section{Background}

The vitamin E family comprises tocopherols $(\alpha, \beta, \gamma$, and $\delta$ forms) and tocotrienols ( $\alpha, \beta, \gamma$, and $\delta$ forms). All isoforms possess lipid antioxidant activity, and $\alpha$-tocopherol possesses the highest vitamin $\mathrm{E}$ activity in mammals [1,2]. Vitamin $E$ is widely used as an antioxidant in foods and oils, as a nutrient additive in poultry and cattle feeds to improve meat quality, and as a supplement in the human diet to help prevent diseases

\footnotetext{
* Correspondence: tetsuyay@res.agr.hokudai.ac.jp

Laboratory of Plant Genetics and Evolution, Graduate School of Agriculture, Hokkaido University, Kita 9 Nishi 9 Sapporo 060-8589, Hokkaido, Japan
}

such as cancer and cardiovascular diseases. The market size is expected to grow because of the increasing interest in functional food and increasing demand for meat products. About $85 \%$ of commercial vitamin $\mathrm{E}$ is synthesized by chemical reaction [3]. This vitamin E usually includes the naturally occurring RRR- $\alpha$-tocopherol and 7 -stereoisomers as secondary products, whose biological activity is only $50 \%-74 \%$ of that of the natural $\alpha$-tocopherol [4]. Thus, it is very important to increase natural vitamin $\mathrm{E}$ production in crops and vegetables [2].

Soybean (Glycine $\max$ (L.) Merr.) is one of the major crops for food, oil, and animal feed. In seed processing,
C Biomed Central

() 2011 Dwiyanti et al; licensee BioMed Central Ltd. This is an Open Access article distributed under the terms of the Creative Commons Attribution License (http://creativecommons.org/licenses/by/2.0), which permits unrestricted use, distribution, and reproduction in any medium, provided the original work is properly cited. 
tocopherols are extracted together with the oil fraction. The tocopherol content is only about $1.5 \%$ of the oil; nevertheless, tocopherols are critical for oxidative stability [5]. Since tocopherols contribute to both the nutritional value of seeds and the oxidative stability of soybean oil, enhancing tocopherol content in soybean will improve its market value. In common soybean cultivars, the main forms of seed tocopherols are $\gamma$-tocopherol and $\delta$-tocopherol, which account for $60 \%$ to $70 \%$ and $20 \%$ to $25 \%$ of the total tocopherol, respectively. The proportion of $\alpha$-tocopherol is usually less than $10 \%$ of total tocopherol in soybean seeds $[1,6,7]$. There have been some efforts to improve soybean vitamin $E$ through genetic engineering. The Arabidopsis VTE4 gene encodes $\gamma$-tocopherol methyltransferase $(\gamma$-TMT), which catalyzes the last step of $\alpha$-tocopherol biosynthesis (Figure 1); overexpression of VTE4 in soybean seeds resulted in $\alpha$-tocopherol elevation to $75 \%$ of total tocopherol. When VTE4 was coexpressed with VTE3, which encodes methyl-6-phytyl-1,4-benzoquinol (MPBQ)-

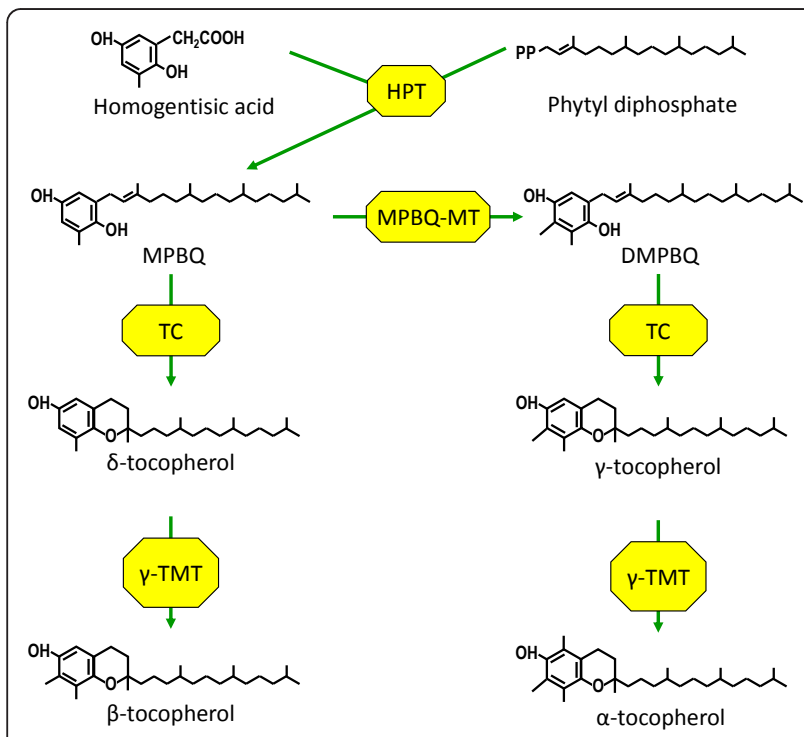

Figure 1 Tocopherol biosynthetic pathway in higher plants Tocopherols consist of a polar chromanol ring and a lipophilic prenyl chain derived from homogentisic acid and phytyl diphosphate. The shikimate pathway produces the homogentisic acid, whereas the 2-C-methyl-d-erythritol-4-phosphate (MEP) pathway produces phytyl diphosphate. Phytyl transferase (HPT) catalyzes the reaction of phytyl diphosphate addition to homogentisic acid, producing the common precursor of the tocopherol biosynthetic pathway, methyl-6-phytyl-1,4-benzoquinone (MPBQ). MPBQ-methyltransferase (MPBQ-MT) adds a methyl alkyl to $M P B Q$, to produce 2,3-dimethyl-6-phytyl-plastoquinol (DMPBQ). MPBQ and DMPBQ are cyclized by tocopherol cyclase (TC) to form $\delta$-tocopherol and $\gamma$-tocopherol, respectively. The last step of tocopherol biosynthesis is methylation of $\delta$-tocopherol and $\gamma$ tocopherol, which produces $\beta$-tocopherol and $\alpha$-tocopherol, respectively. These reactions are catalyzed by $\gamma$-tocopherol methyltransferase ( $\gamma$-TMT). methyltransferase (Figure 1), $\alpha$-tocopherol increased to more than $95 \%$ of total tocopherol, and vitamin E activity increased to up to five times the level in nontransgenic soybean [6]. Meanwhile, overexpression of Perilla frutescens $\gamma$-TMT alone increased $\alpha$-tocopherol to more than $90 \%$ of total tocopherol [8]. Several studies have suggested the importance of other tocopherol forms. For example, $\gamma$-tocopherol may prevent inflammation or improve kidney function, which are distinct from its antioxidant activity $[9,10]$. These studies triggered us to look for natural tocopherol variants, which may have unique characteristics. Such variants may make it possible to breed soybean cultivars with a wide range of $\alpha$ tocopherol (from $10 \%$ to $90 \%$ of total tocopherol), and to develop soybean cultivars tailor-made for certain purposes.

Tocopherols are present in leaves, stems, flower petals, and seeds of higher plants and green algae $[1,11]$. While $\alpha$-tocopherol is usually the predominant form in leaves, there are diverse variations of tocopherol composition in seeds [1]. For example, in soybean, rapeseed (Brassica napus), and Arabidopsis (Arabidopsis thaliana), most of the tocopherols are $\gamma$-tocopherol or $\delta$-tocopherol; in sunflower (Helianthus annuus) and safflower (Carthamus tinctorius) seeds, the content of $\alpha$-tocopherol is more than $95 \%$ of the total tocopherol content $[12,13]$. Variations in $\alpha$-tocopherol content ( $\alpha$-tocopherol weight $[\mu \mathrm{g}]$ per $100 \mathrm{mg}$ seed powder) and concentration $(\alpha-$ tocopherol as a percentage of total tocopherol) have been reported in crops such as maize (from 0.9 to 6.5 $\mu \mathrm{g} 100 \mathrm{mg}^{-1}$ ), sunflower ( $>95 \%$ in wild type and $<10 \%$ in mutants), safflower ( $>85 \%$ in wild type and $<15 \%$ in mutants), rapeseed ( $\alpha / \gamma$-tocopherol ratio ranged from 0.54 to 1.70 ) and in the model plant Arabidopsis [12-16]. Previous studies have shown that variation is also present in soybean. Three soybean varieties with $\alpha$ tocopherol concentration of $20 \%$ to $30 \%$, Keszthelyi Aproszemu Sarga (KAS), Dobrogeance, and Dobrudza 14 Pancevo, were identified through analysis of more than 1,000 cultivars and varieties from soybean germplasms collections [7]. These varieties showed higher $\alpha$ tocopherol content compared to typical cultivars over two planting years, indicating that high $\alpha$-tocopherol content was a stable trait [7]. QTL analysis using Chinese (Hefeng 25) and Canadian (OAC Bayfield) soybean varieties revealed four QTLs for tocopherol content in linkage groups $\mathrm{B} 2, \mathrm{C} 2, \mathrm{D} 1 \mathrm{~b}$, and $\mathrm{I}$, which correspond to chromosome 14, 6, 2, and 20, respectively. However, the causal genes involved in these QTLs are yet to be identified [17].

In our previous study, the genetic characteristics of the high $\alpha$-tocopherol concentration trait were evaluated in an $F_{2}$ population derived from a cross between KAS and a typical variety, Ichihime [18]. $\alpha$-Tocopherol 
concentration of a typical variety is less than $10 \%$ of total tocopherol [6]. Here and in our previous study [18], $\alpha$-tocopherol concentration was defined as the ratio of $\alpha$-tocopherol to total tocopherol, whereas $\alpha$ tocopherol content was defined as the $\alpha$-tocopherol weight $(\mu \mathrm{g})$ per $100 \mathrm{mg}$ soybean seed powder. The broad-sense heritability of the high $\alpha$-tocopherol concentration trait was estimated to be 0.645 [18]. Two simple sequence repeats (SSR) markers, Sat_167 and Sat_243 on linkage groupK (chromosome 9) were strongly correlated with $\alpha$-tocopherol concentration [18]. The relationships between tocopherol forms were also analyzed; $\alpha$-tocopherol concentration had no significant correlation with total tocopherol content, whereas $\gamma$-tocopherol and $\alpha$-tocopherol concentrations showed a strong negative correlation [18].

The strong negative correlation between $\alpha$-tocopherol concentration and $\gamma$-tocopherol concentration suggested that a major gene involved in the biosynthesis pathway of $\alpha$-tocopherol might be responsible for the trait [18]. Tocopherols are biosynthesized from two precursors, homogentisic acid (HGA) and phytyl diphosphate. The two precursors are condensed by HGA phytyl transferase, generating MPBQ. MPBQ is methylated to become 2,3-dimethyl-6-phytyl-1,4-benzoquinol (DMPBQ). MPBQ and DMPBQ are converted by tocopherol cyclase to $\delta$-tocopherol and $\gamma$-tocopherol, respectively. The last step of the tocopherol biosynthesis pathway is methylation of $\delta$-tocopherol and $\gamma$-tocopherol by $\gamma$-tocopherol methyltransferase $(\gamma$-TMT), yielding $\beta$-tocopherol and $\alpha$-tocopherol, respectively (Figure 1) [1].

To elucidate the genetic basis of the high $\alpha$-tocopherol concentration trait in KAS, we performed QTL analysis and fine mapping for $\alpha$-tocopherol concentration by using the population derived from a cross between a typical variety Ichihime and the high $\alpha$-tocopherol variety KAS. The $\gamma$-TMT3, which has high similarity to the Arabidopsis VTE4 gene, was located within a QTL region of approximately $75 \mathrm{~kb}$. The expression level of $\gamma$-TMT3 was higher in developing seeds of plants with the KAS genotype, and the expression elevation was correlated with an increase in $\alpha$-tocopherol content. It is also demonstrated that the transient activity of $\gamma$-TMT3 promoter from KAS was higher than that of Ichihime.

\section{Results}

\section{Mapping the QTL responsible for the high $\alpha$-tocopherol} concentration trait

KAS, a soybean variety with $20 \%$ to $30 \% \alpha$-tocopherol concentration, was crossed to the Japanese cultivar Ichihime ( $\alpha$-tocopherol concentration $<10 \%)$ to obtain a segregating population consisting of $122 \mathrm{~F}_{2}$ plants [18]. These plants were grown in the Hokkaido University greenhouse, where $F_{3}$ seeds of each $F_{2}$ plant were obtained and analyzed for their tocopherol composition. A molecular linkage map was constructed using 152 SSR markers that were polymorphic between Ichihime and KAS. The linkage map covered $3401 \mathrm{cM}$ of the soybean genome and consisted of 20 linkage groups that corresponded to the 20 pairs of soybean chromosomes.

Two population groups were used for QTL analysis. The first population (hereafter, " $F_{2}$ seed population") consisted of $F_{2}$ seeds from the Ichihime $\times$ KAS cross; in this population, tocopherol concentrations were analyzed using the half-seed method (see Materials and Methods). The second population (" $F_{2}$ plant population") consisted of $F_{2}$ plants whose tocopherol content and concentration were evaluated by testing the $F_{2: 3}$ seeds. Multiple QTL Mapping (MQM) analysis was performed using MapQTL5, and the QTL threshold values were determined for each trait by using a 1,000-permutation test [19].

For $\alpha$-tocopherol concentration, only one QTL was detected. The QTL was located on a linkage group K (chromosome 9). MQM analysis revealed that an interval between Sat_243 and KSC138-17 had a strong correlation with $\alpha$-tocopherol concentration, with LOD value 23.4 and phenotypic variation explained (PVE) by this QTL of 55.8\% (Figure 2, Table 1). In our previous study [18], there was a strong correlation between $\alpha$-tocopherol concentration and $\gamma$-tocopherol concentration. Therefore, the QTL analysis was conducted not only for $\alpha$-tocopherol but also for $\gamma$-tocopherol and $\delta$-tocopherol. This was done to elucidate the relationship among tocopherol isoforms and to identify the gene(s) that determine tocopherol composition. From MQM mapping, the QTL located in an interval between Sat_243 and KSC138-17 was also associated with $\gamma$-tocopherol concentration $(\mathrm{LOD}=11.5, \mathrm{PVE}=32.8 \%)$ and $\delta$-tocopherol concentration $(\mathrm{LOD}=5.0, \mathrm{PVE}=16.1 \%)$.

For the $\mathrm{F}_{2}$ plant population, QTLs for tocopherol concentrations and contents were analyzed. The same QTL observed in the analysis of the $\mathrm{F}_{2}$ seed population was also detected for $\alpha$-tocopherol concentration (LOD = 20.2, PVE $=55.0 \%), \gamma$-tocopherol concentration $(\mathrm{LOD}=$ 16.7, $\mathrm{PVE}=48.7 \%)$, and $\delta$-tocopherol concentration $(\mathrm{LOD}=4.8, \mathrm{PVE}=17.0 \%)$. Moreover, this QTL was also responsible for $\alpha$-tocopherol content $(\mathrm{LOD}=20.6$, $\operatorname{PVE}=56.5 \%)$ and $\gamma$-tocopherol content $(\mathrm{LOD}=5.24$, PVE $=17.9 \%)$. For $\delta$-tocopherol concentration, another QTL was detected in interval Sat_244 and Sat_033 of linkage group $M$ (chromosome 12), with LOD value 5.26 and PVE 22.5\%. However, this QTL was not detected in $F_{2}$ seeds analysis.

It has been reported that four QTLs for tocopherol concentrations and contents were detected from QTL analysis in a segregating population derived from a cross 


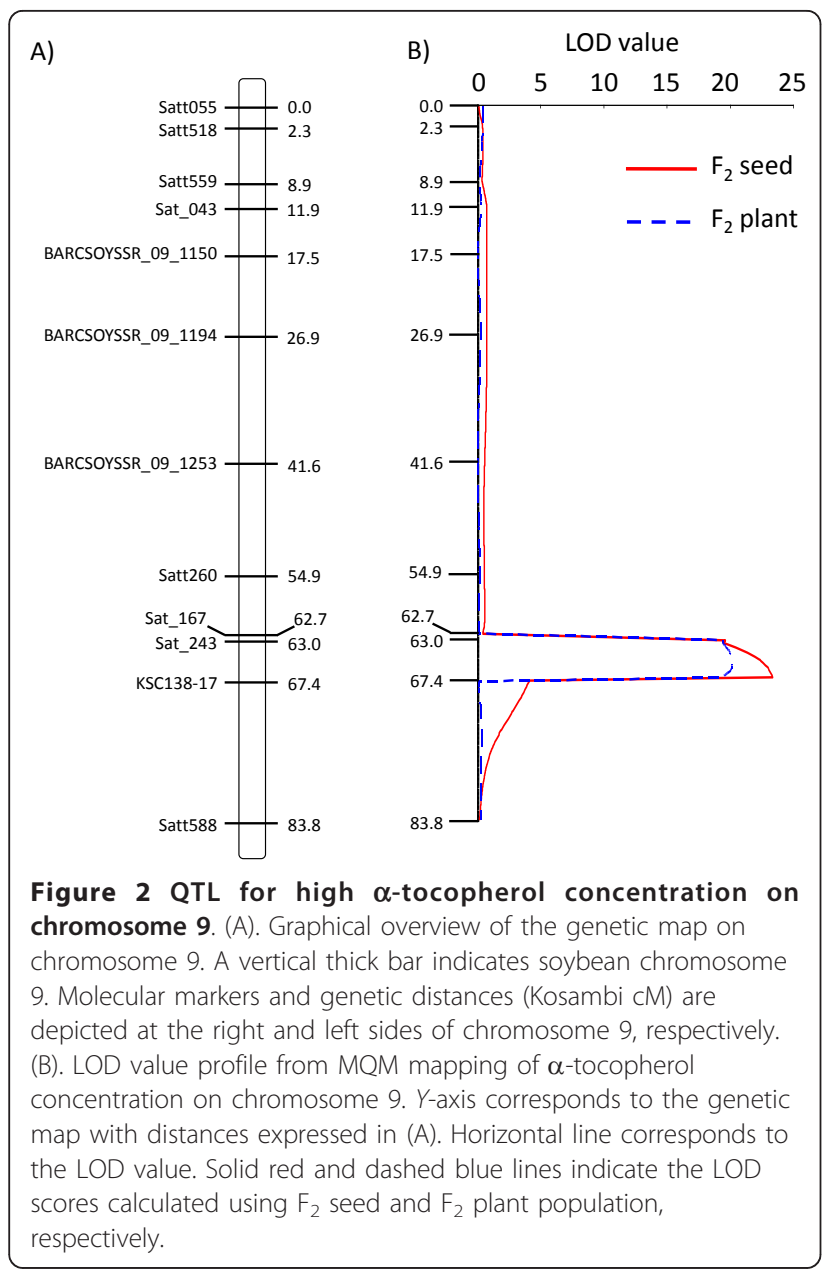

Table 1 QTL associated with tocopherol concentration or content using $F_{2}$ seed and $F_{2}$ plant populations.

\begin{tabular}{lcccc}
\hline Population & Trait $^{\mathbf{a}}$ & LOD $^{\mathbf{b}}$ & PVE (\%) & Add $^{\mathbf{c}}$ \\
\hline$F_{2}$ seed & $\alpha \%$ & 23.4 & 55.8 & 4.158 \\
& $\gamma \%$ & 11.5 & 32.8 & -2.585 \\
& $\delta \%$ & 5.0 & 16.1 & -1.553 \\
\hline$F_{2}$ plant & $\alpha \%$ & 20.2 & 55.0 & 8.009 \\
& $\gamma \%$ & 16.7 & 48.7 & -6.163 \\
& $\delta \%$ & 4.8 & 17.0 & -1.836 \\
& $\alpha$-content & 20.6 & 56.5 & 1.160 \\
& $\gamma$-content & 5.24 & 17.9 & -1.094 \\
\hline
\end{tabular}

QTLs are detected using multiple QTL mapping (MQM) method in MapQTL 5. Permutation test (1000 times) was performed to determine genome wide significance threshold level $(P<0.05)$.

${ }^{a} \alpha \%$ represents $\alpha$-tocopherol concentration, $\gamma \%$ represents $\gamma$-tocopherol concentration, $\delta \%$ represents $\delta$-tocopherol concentration, $\alpha$-content represents $\alpha$-tocopherol content ( $\mu$ g per $100 \mathrm{mg}$ dry weight seeds), and $\gamma$ content represents $\gamma$-tocopherol content ( $\mu \mathrm{g}$ per $100 \mathrm{mg}$ dry weigh seeds). ${ }^{b}$ LOD means logarithm of odds, the peak of LOD value in the QTL range. ${ }^{C}$ PVE means the percentage of phenotypic variance explained for the trait. ${ }^{\mathrm{d}} \mathrm{P}$ ositive values of additive effect (Add) mean the increased effect for the QTL was caused by KAS allele. between a Chinese variety (Hefeng 25) and a high $\alpha$ tocopherol Canadian variety (OAC Bayfield) [17]. However, in this study, no QTL was detected in those regions. This fact suggests that the genetic factor responsible for high $\alpha$-tocopherol concentration in KAS may be different from that in OAC Bayfield.

\section{Identification of candidate gene in the QTL region}

To identify the candidate gene on chromosome 9, fine mapping was performed in the QTL region flanked by the Sat_243 and KSC138-17 markers using $\mathrm{F}_{5}$ lines. The $F_{5}$ lines were derived from the $F_{2}$ plants using single seed descent method. The frequency distribution of $\alpha$-tocopherol concentration in $F_{5}$ lines is shown in Figure 3. The $\alpha$-tocopherol concentration was nearly co-segregated with genotypes of KSC138-17 marker (Figure 3). $\mathrm{F}_{5}$ lines showing recombination in the region between Sat_243 and KSC138-17 were genotyped for newly developed SSR markers located between Sat_243 and KSC13817 (Figure 4A). The fine mapping showed that the candidate gene contributing to high $\alpha$-tocopherol concentration in KAS was likely located in the region between KSC138-10 and KSC138-9, which corresponded to approximately $75 \mathrm{~kb}$ of genomic sequence (Figure 4A).

Based on soybean genome information in the Phytozome database [20], there were 10 predicted genes located in the QTL region between KSC138-10 and KSC138-9 on chromosome 9 (Table 2, Figure 4A). One of them, Glyma09g35680.1, shared $81.8 \%$ peptide similarity with $\gamma$-TMT encoding gene in Arabidopsis, VTE4 [21]. In silico analysis further revealed that two additional genes encoding $\gamma$-TMT exist in the soybean genome: Glyma12g01680.1 and Glyma12g01690.1. Their

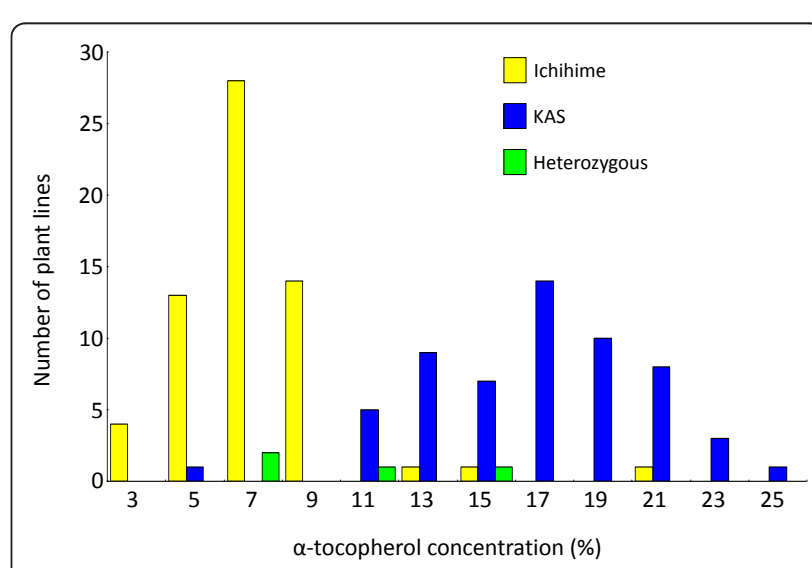

Figure 3 Frequency distribution of phenotypes and genotypes of marker closely linked for $\alpha$-tocopherol concentration in $F_{5}$ plant lines. Frequency distribution of $\alpha$-tocopherol concentration and genotypes of the KSC138-17 marker in $F_{5}$ plant lines. Yellow, blue, and green bars represent plant lines with Ichihime, KAS, and heterozygous genotypes, respectively. 
A)

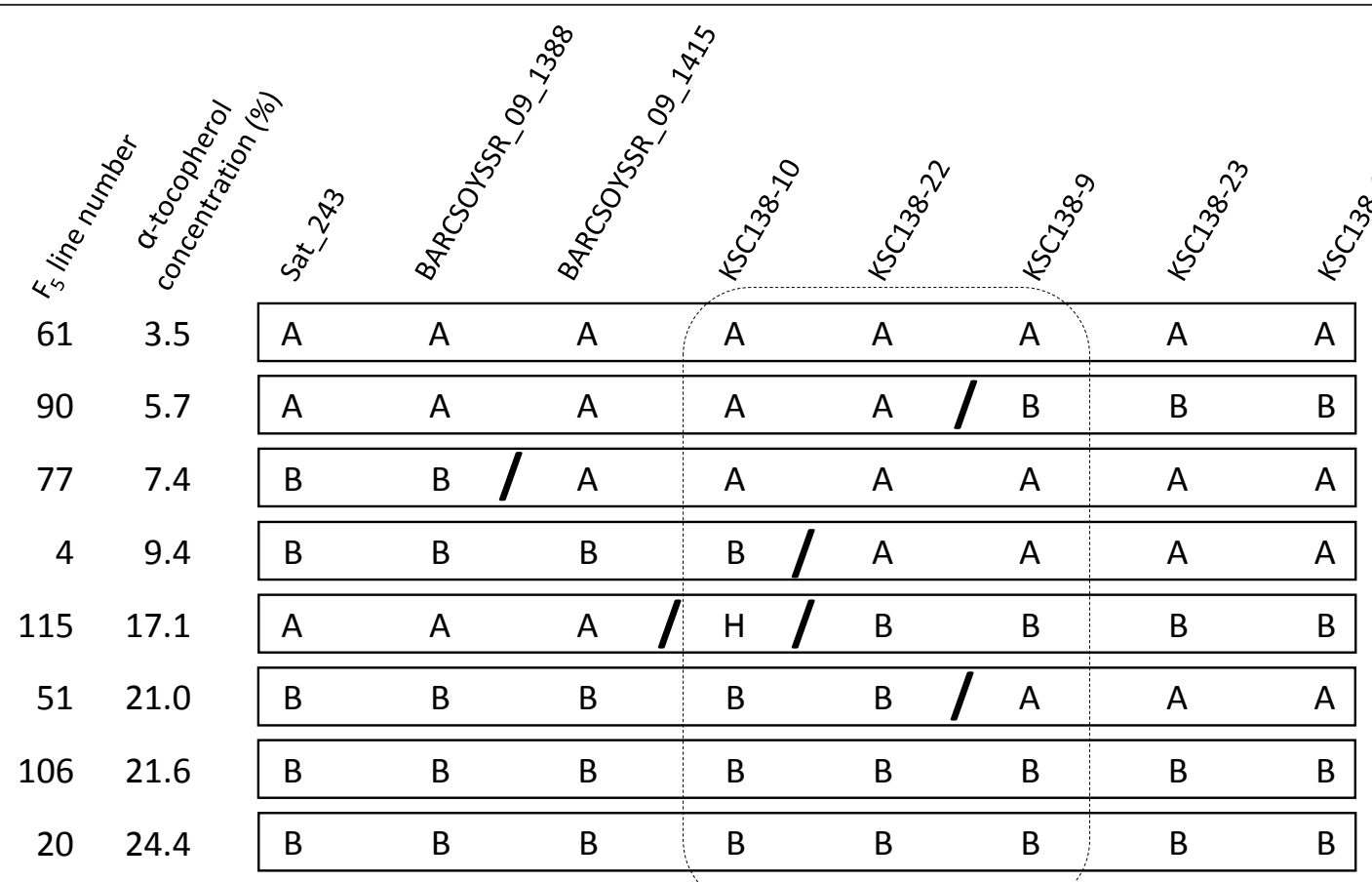

KSC138-10

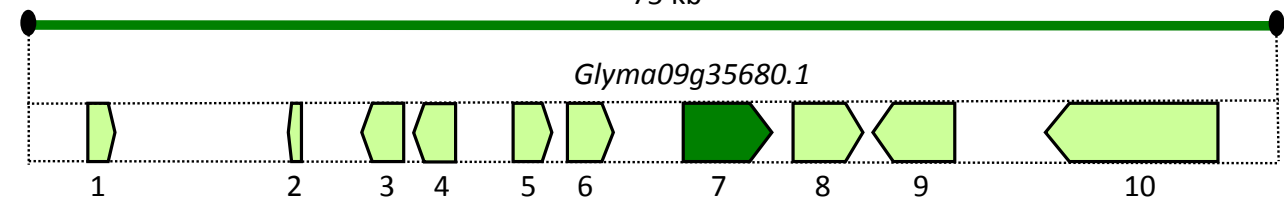

Predicted genes based on Phytozome

B) Glyma09g35680.1 ( $\gamma$-TMT3)

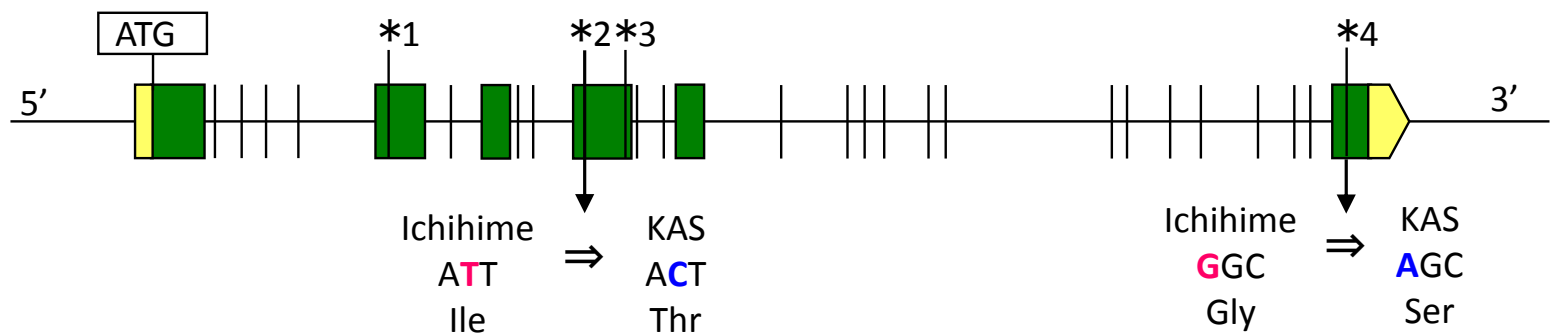

Figure 4 Graphical genotypes of recombinant plants selected from fine mapping and gene structure of $\gamma$-TMT3. (A). Summary of informative $F_{5}$ plant lines used for fine mapping of the QTL responsible for high $\alpha$-tocopherol concentration. Ichihime homozygous genotypes and KAS homozygous genotypes of each marker are represented by 'A' and ' $B$ ', respectively. Heterozygous genotype is represented by ' $H$ '. ' $/$ ' represent recombination positions. The region contributing to high $\alpha$-tocopherol concentration is enclosed by a dashed box. KSC138-9 genotypes were only analyzed for these informative lines. The interval between KSC138-10 and KSC138-9 corresponded to a 75-kb sequence region on chromosome 9. Based on information from the Phytozome database, the region contained 10 predicted genes. Arrows referred to the genes and numbers below arrows correspond to the numbers in Table 2. (B). Gene structure of Glyma09g35680.1 ( $\gamma$-TMT3). The green rectangles and the spaces between the green rectangles represent exons and introns, respectively. The yellow rectangle represents the $5^{\prime}$-UTR region, while the yellow arrow represents the 3'-UTR region. Vertical lines represent genetic polymorphisms (insertion-deletion, SNPs) between Ichihime and KAS. Nucleotide polymorphisms in the exons are indicated by vertical lines and numbers, which are summarized in Table 3. The polymorphisms numbered 2 and 4 are nonsynonymous nucleotide substitutions; the corresponding amino acid changes (Ichihime to KAS) are indicated below the substitution sites. 
Table 2 Predicted genes located in QTL region, based on information of Phytozome database.

\begin{tabular}{ccc}
\hline Number $^{\mathbf{a}}$ & Glyma number & Predicted function \\
\hline 1 & Glyma09g35620.1 & auxin responsive protein \\
2 & Glyma09g35630.1 & auxin responsive protein \\
3 & Glyma09g35640.1 & diphtheria toxin resistance \\
4 & Glyma09g35650.1 & no function annotation \\
5 & Glyma09g35660.1 & amidophosphoribosylpyrophosphate transferase domain \\
6 & Glyma09g35670.1 & amidophosphoribosylpyrophosphate transferase domain \\
7 & Glyma09g35680.1 & -tocopherol methyltransferase $(\gamma-$ TMT $)$ \\
9 & Glyma09g35690.1 & no function annotation \\
10 & Glyma09g35700.1 & no function annotation \\
\hline
\end{tabular}

${ }^{\mathrm{a}}$ Number corresponds to gene number shown in Figure 4A.

predicted polypeptides similarity to VTE4 was $81.4 \%$ and $68.9 \%$, respectively, and both genes were located in tandem on linkage group $\mathrm{H}$ (chromosome 12), separated by $4 \mathrm{~kb}$ genomic sequence. Interestingly, two $\gamma$-TMT genes located in tandem were known to regulate $\alpha$-tocopherol biosynthesis in sunflower [13]. However, no QTL for $\alpha$ tocopherol biosynthesis has been found at linkage group $\mathrm{H}$ located in tandem with Glyma12g01680.1 and Glyma12g01690.1 in soybean. According to the genome information of database Phytozome [20], there is no the conserved synteny between the genomic regions surrounding Glyma12g01680.1 and Glyma12g01690.1, and Glyma09g35680.1. However, in this study, we were unable to determine whether these regions were homeologous to each other or not.

Glyma12g01680.1 and Glyma12g01690.1 were identical to genomic sequences $(\gamma-T M T 1$ and $\gamma$-TMT2, respectively) obtained from Ichihime (Ujiie, unpublished data). Therefore, Glyma12g01680.1 and Glyma12g01690.1 were designated as $\gamma$-TMT1 and $\gamma$-TMT2, respectively. Glyma09g35680.1 was designated as $\gamma$-TMT3. Based on predicted amino acid composition, the three $\gamma$-TMTs were classified into one phylogenetic group, which is a part of a cluster of $\gamma$-TMTs found in dicots (Figure 5).

Except for the N-terminal region, the three $\gamma$-TMTs from soybean share high amino acid similarity with $\gamma$ TMTs found in several other plant species (Figure 6). The plastid is known as a site for $\alpha$-tocopherol biosynthesis [11], therefore the existence of plastid transit peptide signals in the three $\gamma$-TMT proteins using a prediction program of the subcellular localization was searched. As a result of ChloroP analysis, a plastid transit peptide was predicted in $\gamma$-TMT2, but not in $\gamma$ TMT1 or $\gamma$-TMT3 (Figure 6).

In this study, QTLs responsible for $\alpha$-tocopherol concentration and $\gamma$-tocopherol concentration were detected at the same location (linkage group K), strongly supporting the negative correlation between $\alpha$-tocopherol concentration and $\gamma$-tocopherol concentration described in the previous report [18]. On the basis of the biosynthetic pathway of tocopherol (Figure 1), $\gamma$-TMT plays a pivotal role in determining the relative concentrations of $\alpha$-tocopherol and $\gamma$-tocopherol. Therefore, we focused on characterization of the $\gamma$-TMT3 gene. According to the Phytozome database, $\gamma$-TMT3 is $4.3 \mathrm{~kb}$ long and consists of six predicted exons. An approximately $5.5 \mathrm{~kb}$ genomic region containing the entire sequence of $\gamma$ TMT3 gene and its 5'-upstream region was sequenced in both Ichihime and KAS. A total of 26 nucleotide polymorphisms were detected in both exons and introns (Figure 4B). Two nucleotide substitutions in the exons

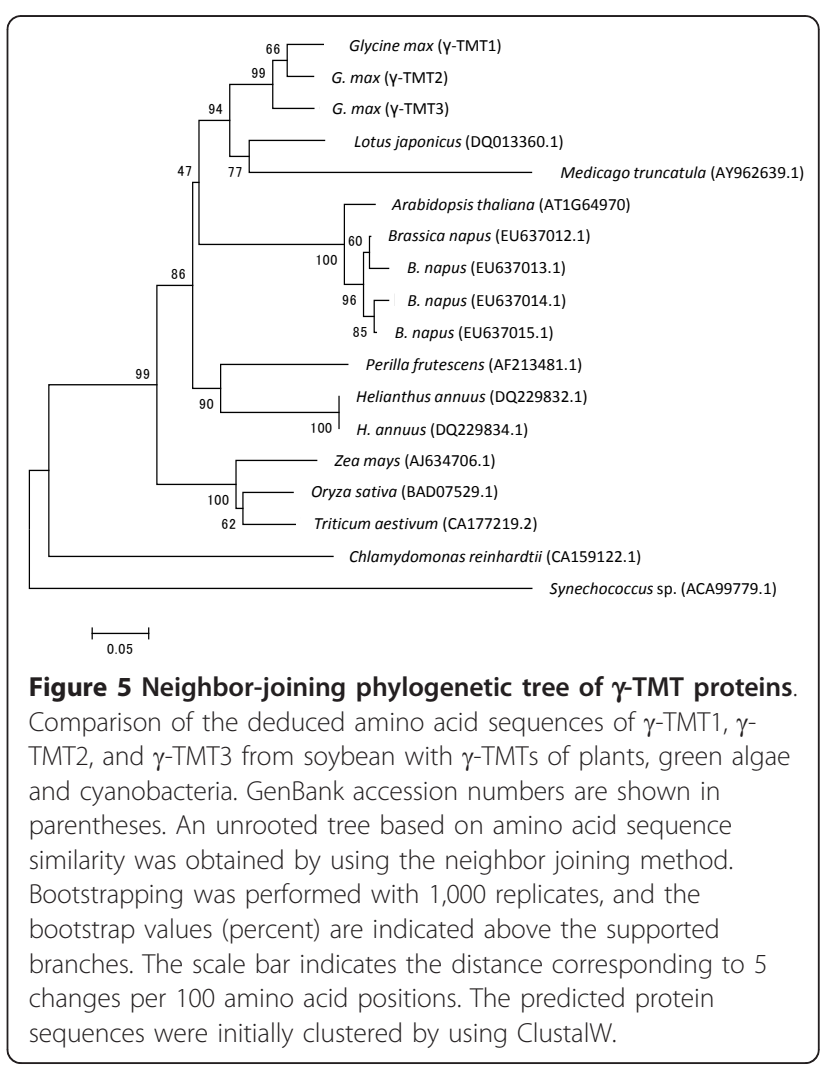




\begin{tabular}{|c|c|c|c|c|c|c|c|c|}
\hline & $\ldots 10$ & & 30 & 40 & 50 & 60 & 70 & 80 \\
\hline A. thaliana (VTE4) & $\begin{array}{l}\cdots \cdots 1 \cdots 1 \\
-\cdots-1-1\end{array}$ & $\begin{array}{l}\cdots \cdot|\cdots| 1 \\
-------M\end{array}$ & KATLAAPSSL & $\begin{array}{l}\ldots 1 \ldots 1 \\
\text { TSLPYRTNSS } \\
\end{array}$ & $\begin{array}{l}\ldots 1 \ldots 1 \\
\text { FGSKSSLLFR }\end{array}$ & & & $\begin{array}{l}\ldots 1 \cdots 1 \\
\text { AAATST-EAL }\end{array}$ \\
\hline G. $\max (\gamma-$ TMT 1$)$ & --------- & -------- & & & & & $---\cdots--M$ & AGKEEKEGKL \\
\hline G. $\max (\gamma-\mathrm{TMT} 2)$ & -------- & -----MATVV & RIPTISCIHI & HTFRSQSPRT & FARIRVGPRS & WAPIRASAAS & SERGEIVLEQ & KPKKDDKKKL \\
\hline G. $\max (\gamma-$ TMT 3$)$ & -------- & ---------- & ---------- & --------- & --------- & --------- & ----MSVEQK & AAGKEEEGKL \\
\hline B. napus & --------- & $-------\underline{\underline{M}}$ & KATLAPSSLI & SLPRHKVSSL & RSPSLLLOSO & RPSSALMTTT T & TASRGSVAVT & AAATSSFEAL \\
\hline P. frutescens & MAEAVTPGIC & TTGWRRGGVH & APTYNISIKP & ATALLVGCTT & KTKSITSFST & DSLRTRGRAR & RPTMSLNAAA & AEMETEMETL \\
\hline H. annuus & --------- & --------- & --------- & --------- & & -MATTAVGVS & ATPMTEKLTA & ADDDQQQQKL \\
\hline z. mays & --------- & $-----\underline{\mathrm{MAH}}$ & AALLHCSQSS & RSLAACRRGS & HYRAPSHVPR & HSRRLRRAVV & SLRPMASSTA & QAPATAPPGL \\
\hline C. reinhardtii & -------- & -------- & -MPSTALQGH & TLPSSSACLG & RATRHVCRVS & TRSRRAVTVR & AGPLETLVKP & LTTLGKVSDL \\
\hline \multirow[t]{2}{*}{ Synechococcus sp. } & --------- & 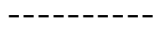 & & & & & & \\
\hline & $\ldots 1 \ldots 1^{90}$ & $\begin{array}{l}100 \\
.1\end{array}$ & $\begin{array}{l}110 \\
.1\end{array}$ & $\begin{array}{l}120 \\
.1\end{array}$ & $\begin{array}{c}130 \\
.1\end{array}$ & $\begin{array}{l}140 \\
.1\end{array}$ & 150 & 160 \\
\hline A. thaliana (VTE4) & RKGIAEFYNE & TSGLWEEIWG & DHMHHGFYDP & DSSVQLSDSG & HKEAQIRMIE & ESLRFAGVTD & -EEEEKKIKK & VVDVGCGIG \\
\hline G. $\max ($ & QKGIAEFYDE & SSGLWENIWG & DHMHHGFYDP & DSTVSLSD-- & HRLAQIRMIQ & ESLRFAS-VS & -EERSKWPKS & IVDVGCGIGE \\
\hline G. $\max (\gamma-T$ & QKGIAEFYDE & SSGLWENIWG & DHMHHGFYDS & DSTVSLSD-- & HRAAQIRMIQ & ESLRFAS-VS & -EERSKWPKS & IVDVGCGIGE \\
\hline G. $\max \left(\gamma-\mathrm{TMT}_{3}\right)$ & QKGIAEFYDE & SSGIWENIWG & DHMHHGFYDP & DSTVSVSD-- & HRAAQIRMIQ & ESLRFASLLS & -ENPSKWPKS & IVDVGCGIGE \\
\hline B. napus & EGIAEFYNE & TSGLWEEIWG & DHMHHGFYDP & DSSVQLSDSG & HREAQIRMIE & ESLRFAGVT- & --EEEKKIKR & VVDVGCGIGE \\
\hline P. fru & GIAEFYDE & SSGVWENIWG & DHMHHGFYEP & AADVSISD-- & HRAAQIRMIE & ESLRFASFSP & TEKPKN & IVDVGCGIGE \\
\hline H. annuus & KKGIAEFYDE & SSGMWENIWG & EHMHHGYYNS & DDVVELSD-- & HRSAQIRMIE & QALTFASVS- & -DDLEKKPKT & IVDVGCGIGE \\
\hline z. mays & KEGIAGLYDE & SSGLWENIWG & DHMHHGFYDS & SEAASMAD- - & HRRAQIRMIE & EALAFAGVPA & SDDPEKTPKT & IVDVGCGIGE \\
\hline C. reinhardtii & KVGIANFYDE & SSELWENMWG & EHMHHGYYPK & GAPVKSNQQ- & --AQIDMIE & ETLKVAGVT- & $-----\mathrm{QAKK}$ & MVDVGCGIGE \\
\hline \multirow[t]{2}{*}{ Synechococcus sp. } & YQQIREFYDA & SSPLWESIWG & EHMHHGFYGL & GGTERLNRRQ & $---A Q I E L I E$ & EFLAWGKVE- & $------\mathrm{QVGN}$ & FVDVGCGIG \\
\hline & $\ldots \mid \ldots 1^{170}$ & $\ldots 1 \ldots 1^{180}$ & $\begin{array}{l}190 \\
.1\end{array}$ & $\begin{array}{l}200 \\
.1\end{array}$ & $\begin{aligned} 210 \\
. .1\end{aligned}$ & $\begin{array}{l}220 \\
.1\end{array}$ & 230 & $\begin{array}{l}240 \\
.1\end{array}$ \\
\hline A. thaliana & SSRYLASKFG & AECI-GITLS & -PVQAKRAND & LAAAQSLAHK & ASFQVADALD & QPFEDGKFDI & VWSMESGEHM & PDKAKFVKEL \\
\hline G. $\max$ & SSRYLAKKFG & ATSV-GITLS & -PVQAQRANA & LAAAQGLDDK & VSFEVADALK & QPFPDGKFDL & VWSMESGEHM & PDKAKFVGEL \\
\hline G. $\max (\gamma-\mathrm{TMT} 2)$ & SSRYLAKKFG & ATSV-GITLS & -PVQAQRANA & LAAAQGLADK & VSFQVADALQ & QPFSDGQFDI & VWSMESGEHM & PDKAKFVGEI \\
\hline G. $\max (\gamma-$ TMT 3$)$ & SSRYLAKKFG & ATSV-GITLS & -PVQAQRANS & LAAAQGLADK & VSFEVADALK & QPFPDGKFDL & VWSMESGEHM & PDKAKFVGEI \\
\hline B. napus & SRYIASKFG & AECI-GITLS & -PVQAKRAND & LAAAQSLSHK & VSFQVADALE & QPFEDGIFDL & VWSMESGEHM & PDKAKFVKEL \\
\hline P. fru & SRYLARKYG & AKLSRAITLS & SPVQAQRAQQ & LADAQGLNGK & VSFEVADALN & QPFPEGKFDI & VWSMESGEHM & PDKKKFVNEL \\
\hline H. annuus & SSRYLARKYG & AECH-GITLS & -PVQAERANA & LAAAAQGLADK & VSFQVADALN & QPFPDGKFDL & VWSMESGEHM & FVSEL \\
\hline z. mays & RYLAKKYG & AQCT-GITLS & -PVQAERGNA & LAAAQGLSDQ & VTLQVADALE & QPFPDGQFDL & VWSMESGEHM & KFVSEL \\
\hline C. reinhardtii & SSRYISRKFG & CTSN-GITLS & -PKQAARANA & LSKEQGFGDK & LQFQVGDALA & QPFEAGAFDI & VWSMESGEHM & PDKKKFVSEL \\
\hline \multirow[t]{2}{*}{ Synechococcus sp. } & STLYLADKFN & AQGV-GITLS & -PVQANRAIA & RATEQNLQDQ & VEFKVADALN & MPFRDGEFDL & VWTLESGEHM & PNKRQFLQEC \\
\hline & $\begin{array}{r}250 \\
\end{array}$ & $\ldots|\ldots|^{260}$ & $\begin{array}{l}270 \\
.1\end{array}$ & $\begin{array}{l}280 \\
.1\end{array}$ & $\left..1 \ldots\right|^{290}$ & $\begin{array}{l}300 \\
.1\end{array}$ & 310 & $\begin{array}{l}320 \\
.1\end{array}$ \\
\hline A. thaliana & VRVAAAPGGRI & IIVTWCHRNL & SAGEEALQPW & EQNILDKICK & TFYLPAWCST & DDYVNLLLSH & SLQDIKCADW & SENVAPFWPA \\
\hline G. $\max (\gamma-\mathrm{TMT} 1)$ & ARVVAAPGATI & IIVTWCHREL & GPDEQSLHPW & EQDLLKKICD & AYYLPAWCSA & SDYVKLLQSL & SLQDIKSEDW & SRFVAPFWPA \\
\hline G. $\max (\gamma-\mathrm{TMT} 2)$ & ARVAAAPGATI & I IVTWCHRDL & GPDEQSLHPW & EQDLLKKICD & AYYLPAWCST & SDYVKLLQSL & SLQDIKSEDW & FVAPFWPA \\
\hline G. $\max (\gamma-\mathrm{TN}$ & ARVAAAPGGTI & IIVTWCHRDI & GPDEQSLLPW & EQDLLKKICD & SYYLPAWCST & SDYVKLLESL & SLQDIKSADW & SPFVAPFWPA \\
\hline B. napus & VRVAAAPGGRI & I IVTWCHRNL & SPGEEALQPW & EQNLIDRICK & TFYLPAWCST & SDYVDLIQSL & SLQDIKCADW & SENVAPFWPA \\
\hline P. frutescer & VRVAAAPGGRI & IIVTWCHRDL & SPSEESLRQE & EKDLLNKICS & AYYLPAWCST & ADYVKLLDSI & SMEDIKSADW & PFWPA \\
\hline H. annuu & TRVAAAPGATI & I IVTWCHRDL & NPGEKSLRPE & EEKILNKICS & SFYLPAWCST & ADYVKLLESL & SLQDIKSADW & APFWPA \\
\hline$z$. mays & ARVVAAPGGTI & I IVTWCHRNL & DPSETSLKPD & ELSLLRRICD & AYYLPDWCSP & SDYVNIAKSL & SLEDIKTADW & SENVAPFWPA \\
\hline C. reinhardtii & ARVCCAPGGTV & IVVTWCHRVL & GPGEAGLRED & EKALIDRINE & AYYLPDWCSV & ADYQKLFEAQ & GLTDIQTRDW & PFWGA \\
\hline \multirow[t]{2}{*}{ Synechococcus sp. } & TRVLKPGGKL & LMATWCHRPT & DSVAGTLTPA & EQKHLEDLYR & IYCLPYVISI & PDYQAIATEC & לחסרחדיתות זם & \\
\hline & $\begin{aligned} & 330 \\
& \ldots 1 \ldots 1\end{aligned}$ & $\ldots 1 \ldots 1^{340}$ & $\begin{array}{r}350 \\
.1\end{array}$ & $\begin{array}{l}360 \\
.1\end{array}$ & & & & \\
\hline A. thali & IRTALTWKG & LVSLLRSGMK & SIKGALTMPL & MIEGYKKGVI & KFGIITCQKP & $L^{*--}$ & & \\
\hline G. $\max (\gamma-\mathrm{T}$ & VIRSALTWNG & LTSLLRSGLK & AIKGALAMPL & MIKGYKKNLI & KFAIITCRKP & $E^{*---}$ & & \\
\hline G. $\max (\gamma$ & IRSAFTWKG & LTSLISSGQK & TIKGALAMPL & MIEGYKKDLI & KFAIITCRKP & $E^{\star}---$ & & \\
\hline G. $\max$ & [RTALTWNG & LTSLLRSGLK & TIKGALAMPL & MIKGYKKDLI & KFSIITCRKP & $E^{\star}---$ & & \\
\hline B. napus & RTALTWKG & LVSLLRSGMK & SIKGALTMPL & MIEGYKKGVI & KFGIITCQKP & $L^{\star}---$ & & \\
\hline P. frut & KSALTWKG & ITSLLRSGWK & TIRGAMVMPL & MIEGYKKGVI & KFAIITCRKP & $A S^{*}--$ & & \\
\hline H. annur & IKTALSWKG & ITSLLRSGWK & SIRGAMVMPL & MIEGFKKDVI & KFSIITCKKP & $\star---$ & & \\
\hline z. mays & VIKSALTWKG & FTSLLTTGWK & TIRGAMVMPL & MIQGYKKGLI & KFTIITCRKP & GAA- & & \\
\hline C. reinha & VIATALTSEG & LAGLAKAGWT & TIKGALVMPL & MAEGFRRGLI & KFNLISGRKL & $2 Q^{*--}$ & & \\
\hline Synecho & VIDSALTPEA & VFGILKAGWQ & TLQGALALDL & MKSGFRRGLI & RYGLLQATKP & KA-- & & \\
\hline \multicolumn{9}{|c|}{$\begin{array}{l}\text { Figure } 6 \text { Amino acid sequence alignment of } \gamma \text {-TMT proteins. Comparison of the deduced amino acid sequences of } \gamma \text {-TMT1, } \gamma \text {-TMT2, and } \gamma \text { - } \\
\text { TMT3 with those of other plants green algae and cyanobacterium. For B. napus (EU637012.1) and H. annuus (DQ229832.1), only one of the } \\
\text { sequences was used for alignment. The sequences were compared with A. thaliana } \gamma \text {-TMT (VTE4) as a standard; identical residues in other } \\
\text { sequences are shaded, and gaps introduced for alignment purposes are indicated by dashes (-). Lines under amino acid sequences represented } \\
\text { plastid transit peptides, which were predicted by using ChloroP1.1 [37]. Blocks surrounded by black boxes are conserved SAM-binding domains, } \\
\text { as reported by Shintani and DellaPenna [21]. }\end{array}$} \\
\hline
\end{tabular}


Table 3 Polymorphisms in exon region of $\gamma$-TMT3 gene.

\begin{tabular}{ccccccc}
\hline Cultivar name & *1 $^{*} \mathbf{2}$ & $* \mathbf{3}$ & $* \mathbf{4}$ & $\begin{array}{c}\boldsymbol{\alpha} \text {-Tocopherol } \\
\text { concentration } \\
\text { (\%) }\end{array}$ & $\begin{array}{c}\text { Harvesting } \\
\text { year }\end{array}$ \\
\hline Williams 82 & T & C & C & A & $3.88 \pm 0.32$ & 2009 \\
Ichihime & T & T & A & G & $1.99 \pm 0.08$ & 2008 \\
Toyokomachi & T & C & A & G & $4.84 \pm 0.58$ & 2008 \\
KAS & G & C & C & A & $19.25 \pm 2.22$ & 2008 \\
Dobrogeance & G & C & C & A & $18.06 \pm 2.20$ & 2006 \\
Dobrudza 14 & G & C & C & A & $19.38 \pm 1.14$ & 2008 \\
Pancevo & & & & & &
\end{tabular}

Ordinary cultivars (Williams 82, Ichihime, and Toyokomachi) and high $\alpha$ tocopherol cultivars (KAS, Dobrogeance, Dobrudza 14 Pancevo) were used for analysis. Polymorphisms in exons are depicted by *1, *2, *3, *4 (see Figure.4B), $\alpha$-Tocopherol concentration data are represented as mean \pm SD of the values obtained from triplicate experiments. All plants were grown in Hokkaido University experimental farm.

led to amino acid alterations. They seemed not to be nucleotide polymorphisms involved in the high $\alpha$-tocopherol concentration, because Williams 82 which possessed identical nucleotides to KAS at these two positions showed low $\alpha$-tocopherol concentration same as that of Ichihime (Table 3). Therefore, the 5'-upstream regions from the transcription initiation site of $\gamma$-TMT3 between high $\alpha$-tocopherol and typical soybeans were compared. Approximately $1.2 \mathrm{~kb}$ of the $5^{\prime}$-upstream region was sequenced in six varieties with high $\alpha$-tocopherol concentration (KAS, Dobrogeance, and Dobrudza 14 Pancevo) and typical varieties (Ichihime, Toyokomachi, and Williams 82). Sequences alignment revealed that 10 singlenucleotide polymorphisms (SNPs) were observed between the two groups. Of these, two SNPs were located in gene transcriptional regulation domains: a MYB binding site and a CAAT box at positions -612 and -46 , respectively, from the predicted transcriptional start site of Williams 82 (Figure 7). The motif of the CAAT box in high $\alpha$-tocopherol soybeans was "CAAAT", whereas the motif in typical soybeans was "CCAAT". "CCAAT" is the canonical sequence of the CAAT box, but the "CAAAT" motif is also recognized as a CAAT box motif in mammals $[22,23]$. On the other hand, the MYB binding site ("CTGTTA") was observed only in high $\alpha$-tocopherol soybeans. The motif is recognized by MYB transcription factors in maize and Arabidopsis [24].

\section{Relationship between $\alpha$-tocopherol concentration and expression levels of $\gamma$-TMT genes}

The expression level of $\gamma$-TMT3 could affect $\alpha$-tocopherol content and concentration was investigated because the polymorphisms correlated to $\alpha$-tocopherol concentration were found in the transcriptional regulatory domain of $\gamma$-TMT3.

$\mathrm{F}_{5}-24$, an $\mathrm{F}_{5}$ heterogeneous inbred family (HIF) [25] which was heterozygous for the genomic region

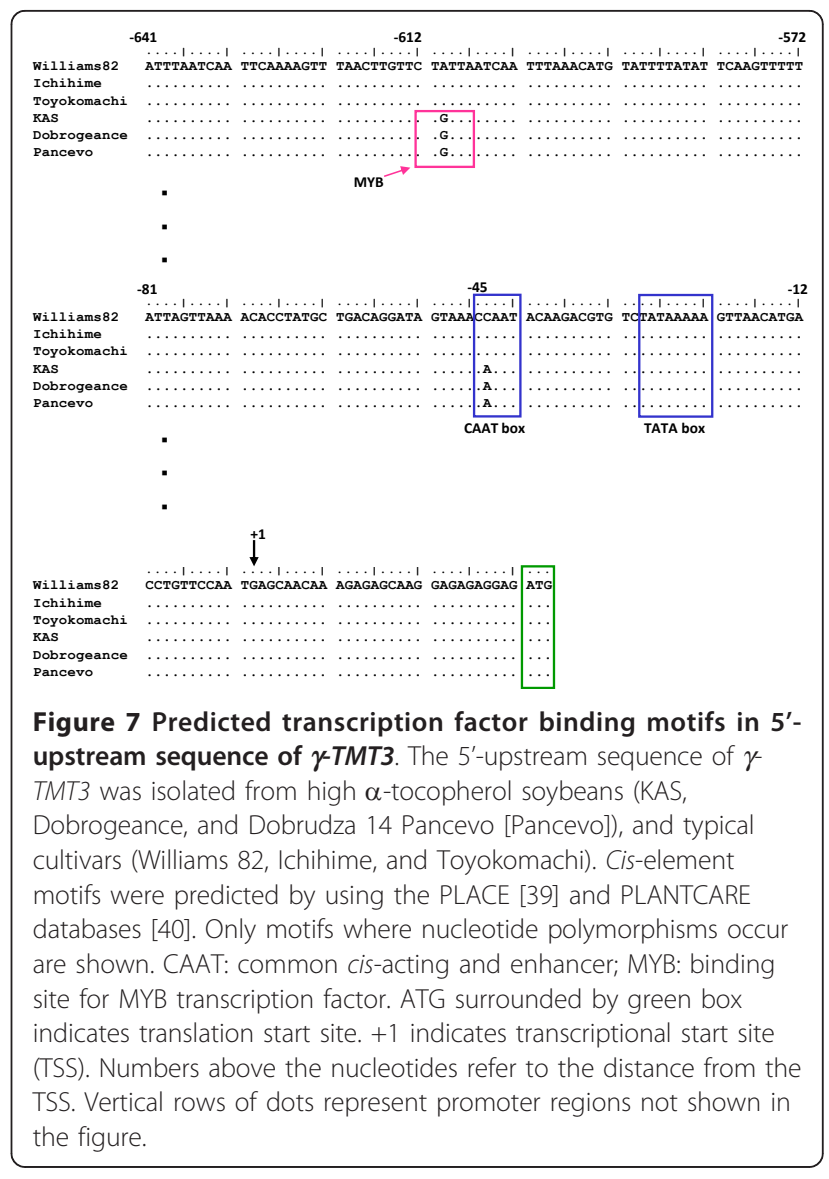

surrounding $\gamma$-TMT3 and homozygous throughout almost entire genome was used to generate plants homozygous for the $\gamma$-TMT3 genomic region from Ichihime and that from KAS; these are referred to as Ichihime lines and KAS lines, respectively. Three lines homozygous for the Ichihime allele $\left(\mathrm{F}_{5}-24-10, \mathrm{~F}_{5}-24-14\right.$, and $\left.F_{5}-24-15\right)$ and three lines homozygous for the KAS allele $\left(F_{5}-24-7, F_{5}-24-18\right.$, and $\left.F_{5}-24-22\right)$ were generated. From each plant, developing seeds were collected at 30 , 40, and 50 days after flowering (DAF).

As shown in Figure 8A, $\alpha$-tocopherol concentration increased toward seed maturation. At all developmental stages, the $\alpha$-tocopherol concentration was significantly higher in the KAS lines than in the Ichihime lines $(P<$ $0.05)$. In 30-DAF seeds, $\alpha$-tocopherol concentration in the KAS lines was 1.2 to 2.4 times that of the Ichihime lines. The difference between the Ichihime lines and the KAS lines was greater toward seed maturation. At 50 DAF, the $\alpha$-tocopherol concentration of KAS lines was up to three times that of the Ichihime lines. There was no significant difference $(P<0.05)$ in $\gamma$-tocopherol concentration between the Ichihime lines and the KAS lines (Figure 8B). Compared to other tocopherol forms, $\delta$ tocopherol concentration in the KAS lines was 
A)

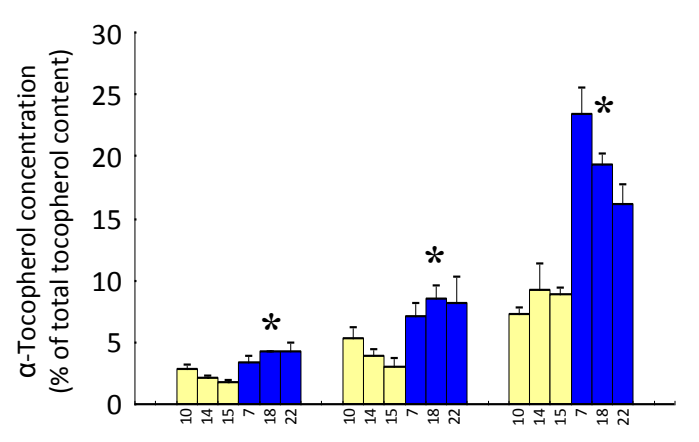

B)

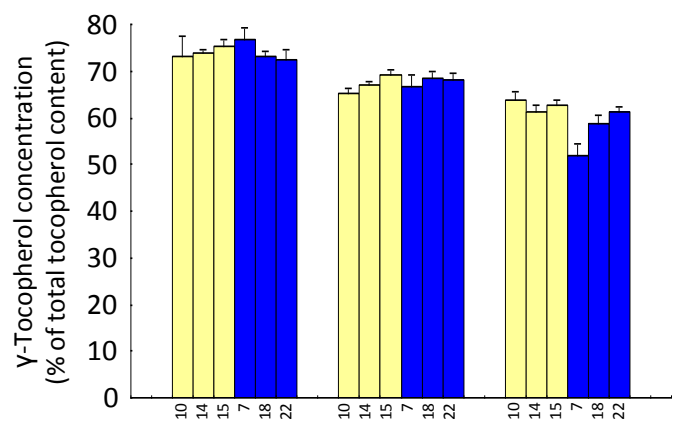

C)

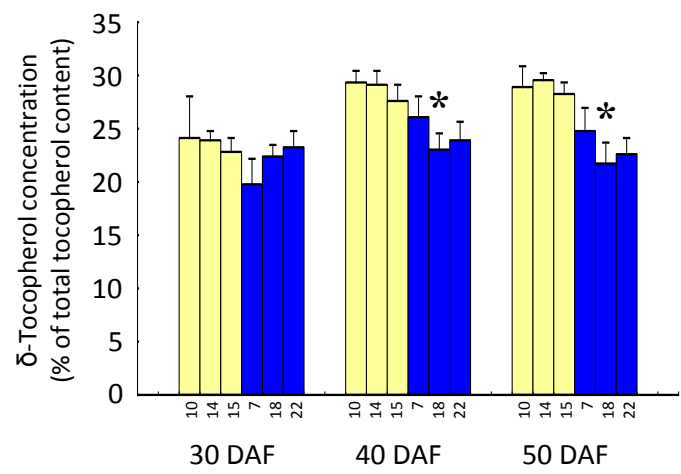

Figure 8 Tocopherol concentration in developing seeds of HIFderived lines. Developing seeds of HIF-derived lines homozygous for either the Ichihime allele for $\gamma$-TMT3 $\left(F_{5}-24-10, F_{5}-24-14\right.$, and $F_{5}-$ 24-15; yellow bars) or the KAS allele for $\gamma$-TMT3 ( $F_{5}-24-7, F_{5}-24-18$, and $F_{5}-24-22$; blue bars) were used for analysis. Seeds were analyzed at 30 days after flowering (DAF), $40 \mathrm{DAF}$, and $50 \mathrm{DAF}$. The concentrations of $\alpha$-tocopherol (A), $\gamma$-tocopherol (B), and $\delta$ tocopherol (C) were calculated as the percentage of the tocopherol isoform in total tocopherol content. Data are represented as mean \pm SD of the values obtained from triplicate experiments. For each developmental stage, significant differences between the Ichihime genotype group and the KAS genotype group (confidence interval 95\%) are shown with asterisks.

significantly lower $(P<0.05)$ than in the Ichihime lines at 40 and 50 DAF (Figure $8 \mathrm{C}$ ).

$\alpha$-Tocopherol content in the KAS lines was significantly higher than that of the Ichihime lines at all seed developmental stages (Figure 9A), and the difference was the greatest at $50 \mathrm{DAF}$, showing the same tendency as $\alpha$-tocopherol concentration. In contrast, total tocopherol content did not show significant $(P<0.05)$ change during seed maturation (Figure 9B). It is concluded from these results that the $\alpha$-tocopherol concentration increase resulted mainly from the increase in $\alpha$ tocopherol content. Among the other tocopherol forms, $\gamma$-tocopherol decreased slightly toward seed maturation, whereas $\delta$-tocopherol content increased until $40 \mathrm{DAF}$ then decreased toward maturation (Figure 9C and 9D). A significant difference $(P<0.05)$ between the KAS lines and the Ichihime lines was observed for $\delta$-tocopherol content at 40 DAF stage, and a slight but not significant difference $(P<0.05)$ between KAS lines and Ichihime lines was also observed for $\delta$-tocopherol content at 50 DAF stage. No significant difference $(P<$ $0.05)$ was observed for $\gamma$-tocopherol content at any developmental stage (Figure 9C).

The expression levels of $\gamma$-TMT1, $\gamma$-TMT2 and $\gamma$ TMT3 were evaluated by quantitative RT-PCR at three seed developmental stages (Figure 10). The expression level was normalized based on the expression of a reference gene, 18S rRNA which was given as a proper reference gene in a gene expression analysis [26]. The expression of all three $\gamma$-TMT genes reached the highest level at $40 \mathrm{DAF}$, when seed size reached the maximum. $\gamma$-TMT1 and $\gamma$-TMT2 showed no difference $(P<0.05)$ in expression level between the Ichihime lines and the KAS lines. $\gamma$-TMT3 showed significant differences $(P<$ $0.05)$ in expression between the Ichihime lines and the KAS lines at both 30 and 40 DAF. The expression level of $\gamma$-TMT3 in the KAS lines was 1.5 to 3 times that of the Ichihime lines at 30 and 40 DAF $(P<0.05)$. Expression levels of $\gamma$-TMT1, $\gamma$-TMT2, and $\gamma$-TMT3 were also analyzed in fully expanded leaves of Ichihime and KAS. Interestingly, the transcriptional level of $\gamma$-TMT3 in KAS leaves was also higher than that in Ichihime leaves, the same pattern as was observed in developing seeds (Figure 11).

\section{Activity of $\gamma$-TMT3 promoter of Ichihime and KAS}

Since the expression level of $\gamma$-TMT3 was different in leaves as well as in developing seeds (Figure 11), we measured the transient activities of $\gamma$-TMT3 promoters in transgenic Arabidopsis leaves expressing GUS reporter gene under the control of $\gamma$-TMT3 promoter from KAS or Ichihime. The GUS activity of $10 \mathrm{~T}_{2}$ plants carrying the $\gamma$-TMT3 promoter from Ichihime and $11 \mathrm{~T}_{2}$ plants carrying the $\gamma$-TMT3 promoter from KAS were shown in Figure 12A and 12B. Mean of the GUS activity in transformants carrying $\gamma$-TMT3 promoter of KAS was 385.5 pmol 4-MU min ${ }^{-1} \mathrm{mg}^{-1}$ protein, whereas the mean in transformants with Ichihime promoter was 100.53 pmol 4-MU $\min ^{-1} \mathrm{mg}^{-1}$ protein. $\mathrm{F}$ test analysis for log- 


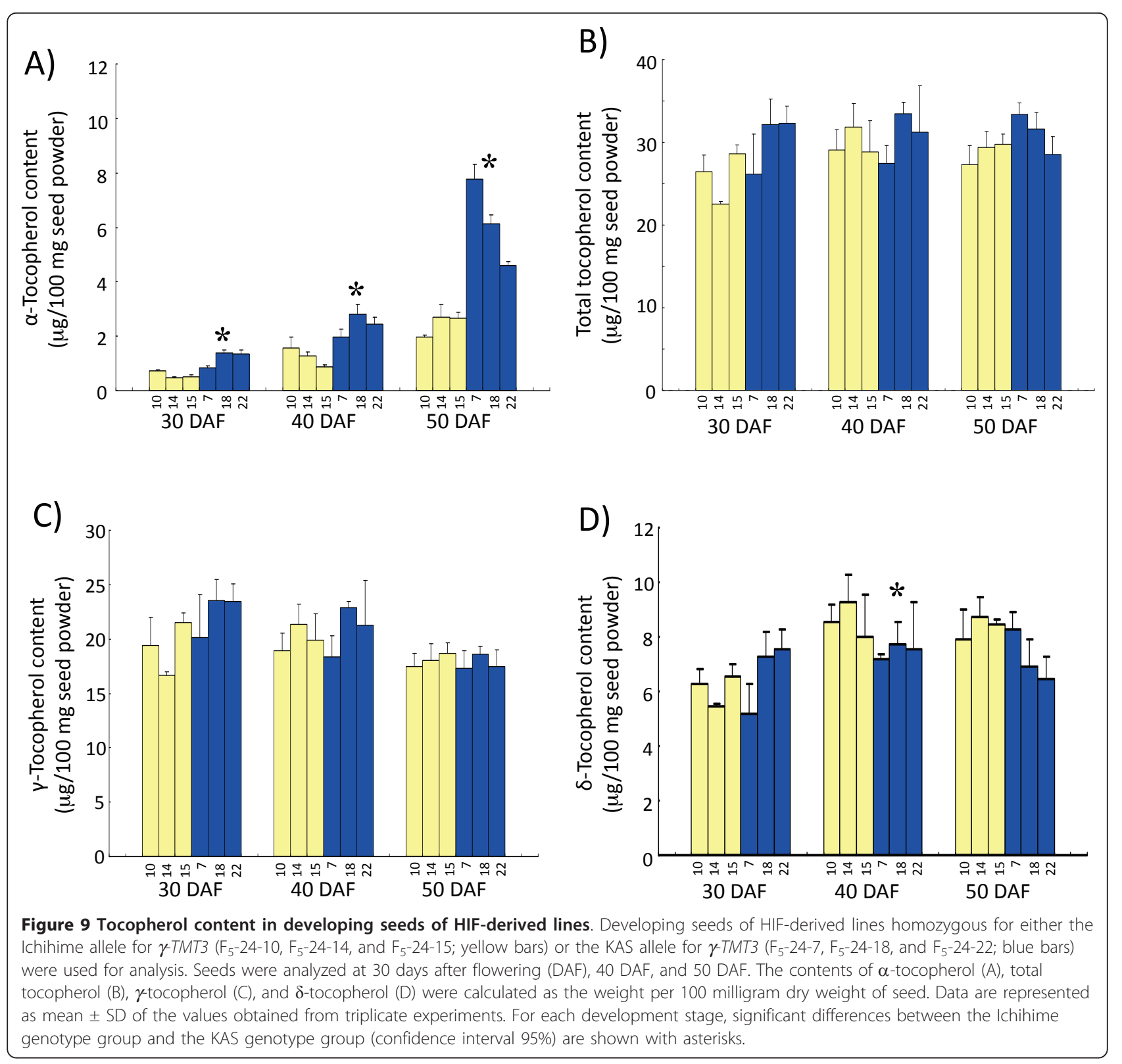

transformed data showed that the activity of $\gamma-T M T 3$ promoter of KAS was significantly higher than that of Ichihime promoter $(\mathrm{F}=7.170, P=0.015)$.

\section{Discussion}

$\gamma$-TMT3 is the candidate gene for high $\alpha$-tocopherol concentration in KAS

In the previous study, two SSR markers, Sat_243 and Sat_167 on a linkage group K (chromosome 9) were strongly associated with $\alpha$-tocopherol concentration. In this study, we confirmed that the QTL in interval Sat_243 and KSC138-17 was associated with $\alpha$-tocopherol concentration, $\gamma$-tocopherol concentration, $\alpha$ tocopherol content, and $\gamma$-tocopherol content. The QTL positively regulated $\alpha$-tocopherol concentration and $\alpha$ tocopherol content, and negatively regulated $\gamma$-tocopherol concentration and $\gamma$-tocopherol content (Table 1 ), indicating that the candidate gene is directly related to conversion of $\gamma$-tocopherol to $\alpha$-tocopherol. Fine mapping using $\mathrm{F}_{5}$ lines showed that $\gamma$-TMT3 was located in a QTL region. This study focused on the molecular characterization of $\gamma$-TMT3 gene.

Based on sequencing analysis and gene expression analysis, the nucleotide polymorphisms in $\gamma$-TMT3 promoter region might increase the expression level of $\gamma$ TMT3 in developing seeds of KAS, and subsequently associated with high $\alpha$-tocopherol concentration in KAS seeds. Transient GUS assay for the 1.2-kb promoter 


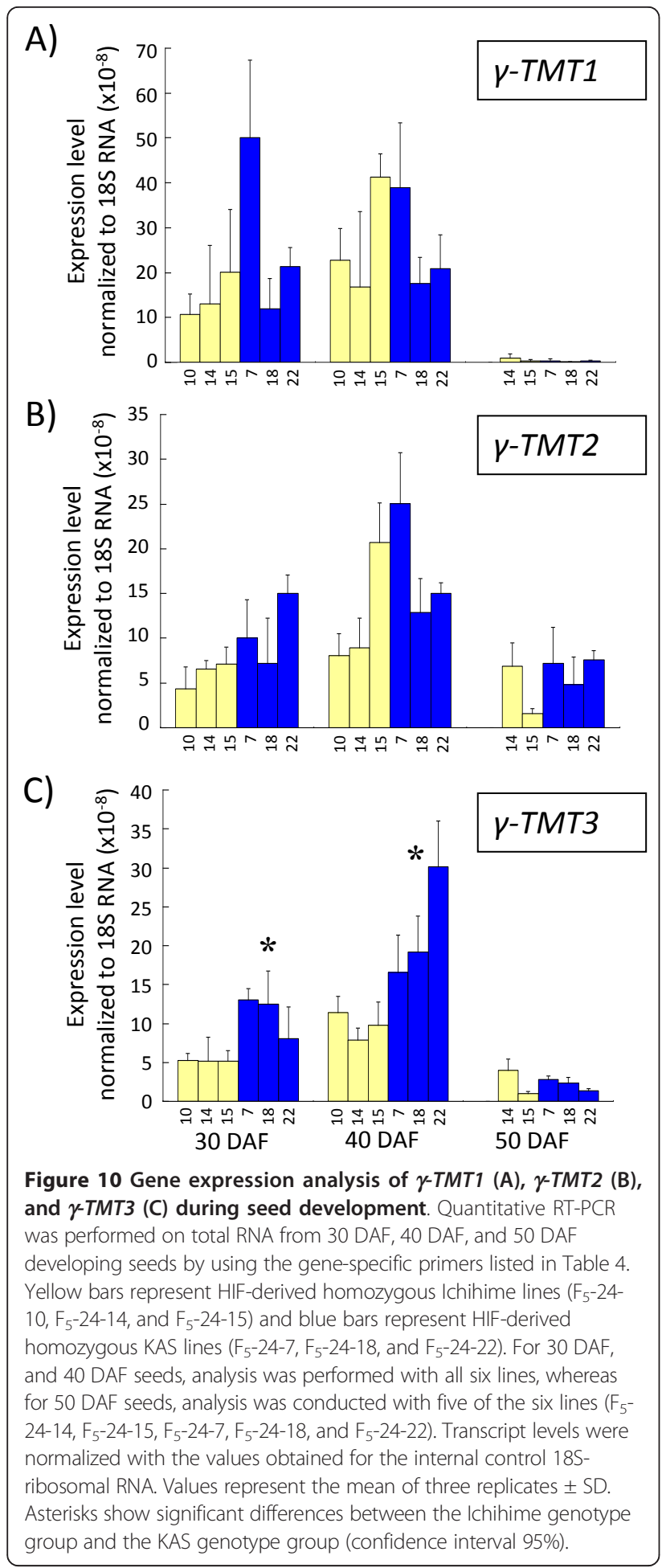

region of $\gamma$-TMT3 from KAS and Ichihime also supported our view that different $\gamma$-TMT3 expression between KAS and Ichihime could be, at least partly, attributed to the difference in the promoter sequence, although we cannot exclude the possibility that some

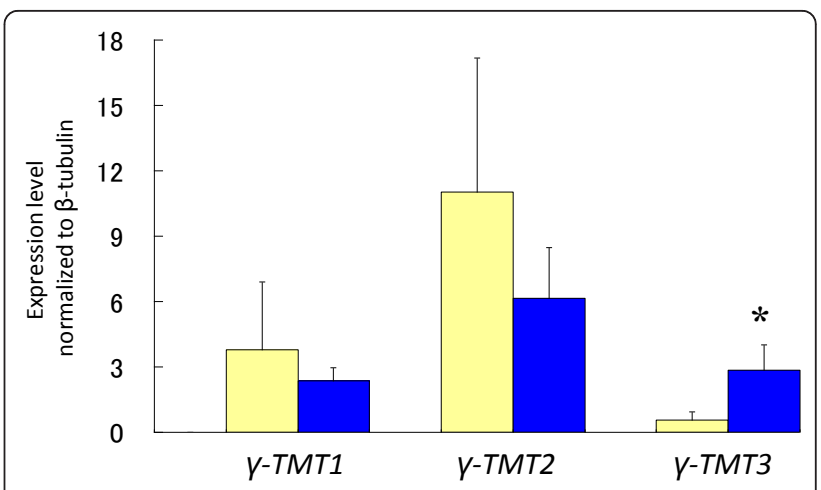

Figure 11 Gene expression analysis of $\gamma$-TMT1, $\gamma$-TMT2, and $\gamma$ TMT3 in leaves of Ichihime and KAS. Quantitative RT-PCR was performed on total RNA from leaves using the gene-specific primers listed in Table 5. Yellow bars represent Ichihime and blue bars represent KAS. Transcript levels were normalized with the values obtained for the internal control ( $\beta$-tubulin mRNA). Values represent the mean of three replicates \pm SD. Asterisks show significant difference between the Ichihime genotype group and the KAS genotype group (confidence interval 95\%).

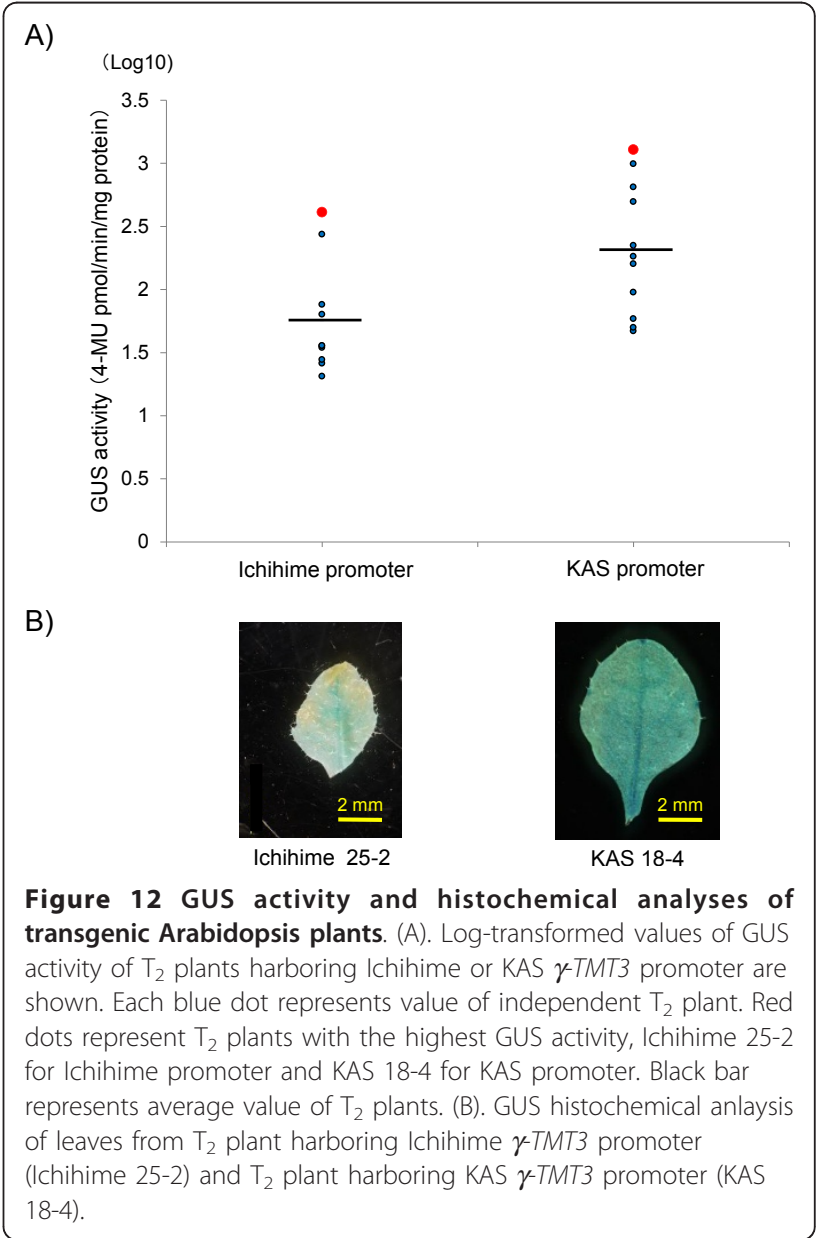


cis-elements affecting the $\gamma$-TMT3 expression is located outside of $1.2-\mathrm{kb}$ upstream of the transcriptional start site.

Two of the polymorphisms were located in transcription factor binding motifs in the 5'-upstream region of the $\gamma$-TMT3 gene in high $\alpha$-tocopherol soybeans (Figure 7). The first mutation is located in a CAAT box, which acts as an enhancer for gene expression. The canonical sequence of CAAT box is "CCAAT", which is the sequence found in Ichihime. The KAS type is "CAAAT", which is not canonical but is recognized as a functional CAAT box in mouse [22]. At present, we do not know any report that mutation in a CAAT box can enhance gene expression. The second mutation produced a MYB binding site in the KAS promoter; this same sequence ("CTGTTA") is also found in the caffeic acid O-methyltransferase gene promoter of Arabidopsis [24]. In Arabidopsis, the "CTGTTA" motif is recognized by maize MYB transcription factors ZmMYB31 and ZmMYB42 [24]. Further analysis of these cis-elements will provide information of whether these polymorphisms contribute to alteration in the promoter activity.

\section{Regulation of tocopherol content and concentration in soybean}

The tocopherol content analysis in this study provides important information about regulation of the tocopherol content and concentration in soybean. In the KAS lines, $\delta$-tocopherol content was lower than in Ichihime lines at 40 DAF. However, the content of $\gamma$-tocopherol did not differ between KAS lines and Ichihime lines. Since the peaks from $\gamma$-tocopherol and $\beta$-tocopherol could not be separated by the analytic method used in this study, it is suggested that increase in $\beta$ tocopherol content might mask a decrease in the content of $\gamma$-tocopherol. Thus, $\gamma$-TMT3 may catalyze both $\gamma$-tocopherol and $\delta$-tocopherol conversion to $\alpha$-tocopherol and $\beta$-tocopherol, respectively (Figure 1). The $\delta$ tocopherol decrease and $\alpha$-tocopherol increase in KAS lines also raises the question of whether $\gamma$-TMT3 can also catalyze the methylation of MPBQ to DMPBQ. It is reported that Arabidopsis $\gamma$-TMT (VTE4) was not active toward MPBQ in vitro [27]. In soybean, there was little similarity in amino acid sequences between $\gamma$-TMTs and MPBQ-MTs, indicating that soybean $\gamma$-TMTs might not be active toward MPBQ. Further analysis of the enzymatic activity and substrate specificity of $\gamma$-TMT3 will provide more information about the biochemical properties of $\gamma$-TMT3.

\section{The possibility of functional differentiation of $\gamma$-TMT proteins}

$\gamma$-TMT1, $\gamma$-TMT2, and $\gamma$-TMT3 proteins have amino acid similarity more than $90 \%$ and two SAM binding domains (Figure 6), suggesting that they all possess the $\gamma$-TMT activity that catalyzes the conversion of $\gamma$-tocopherol to $\alpha$-tocopherol. It is elucidated that three $\gamma$ TMT genes $(\gamma$-TMT1, $\gamma$-TMT2, and $\gamma$-TMT3) were expressed in leaves and developing seeds where $\alpha$-tocopherol was synthesized and accumulated (Figure 10, Figure 11). However, it is indicated that alteration in expression level of $\gamma$-TMT3 alone could increase both $\alpha$-tocopherol concentration and $\alpha$-tocopherol content to up to 2.4 times that of typical soybean (Figure 8A, 9A). If $\gamma$-TMT1 or $\gamma$-TMT2 mutations are also able to enhance $\alpha$-tocopherol accumulation, gene pyramiding of these $\gamma$-TMT variants will enable us to develop new soybean varieties with higher $\alpha$-tocopherol concentration or content than KAS. $\gamma$-TMT1, $\gamma$-TMT2, and $\gamma$-TMT3 polypeptides showed differences in their NH2-terminal region (Figure 6), although they shared high amino acid similarity with $\gamma$-TMTs found in several other plant species (Figure 6). Interestingly, no plastid signal peptide was predicted in $\gamma$-TMT1 and $\gamma$-TMT3 based on in silico analysis. $\alpha$-Tocopherol is known to be localized and be synthesized in plastids [11], and enzymes involved in its biosynthesis are localized inside the plastid $[11,28]$. Further analysis about the subcellular localization of $\gamma$-TMT1 and $\gamma$-TMT3 might elucidate the functional diversifications in $\gamma$-TMT proteins for the regulation of $\alpha$-tocopherol biosynthesis in soybean.

\section{Conclusions}

In this work, we identified a QTL responsible for genetic regulation of the high $\alpha$-tocopherol concentration in KAS. In addition to regulating $\alpha$-tocopherol concentration, this QTL also affected $\gamma$-tocopherol concentration and $\delta$-tocopherol concentration. Thus it is suggested that a gene underlying this QTL regulates tocopherol concentration. Through fine mapping, $\gamma$ TMT3 was identified as a candidate gene for the high $\alpha$-tocopherol concentration trait. $\gamma$-TMT3 encodes $\gamma$ tocopherol methyltransferase, which catalyzes the methylation $\gamma$-tocopherol to $\alpha$-tocopherol. The expression of $\gamma$-TMT3 in the developing seeds of KAS lines was higher than in the seeds of Ichihime lines. Concomitantly, $\gamma$-TMT3 expression was higher in leaves of KAS than in those of Ichihime. Taken these results together, it is concluded that the promoter region polymorphisms caused higher $\gamma$-TMT3 expression in KAS, resulting in a higher $\alpha$-tocopherol concentration. A transient activity analysis of $\gamma$-TMT3 promoters showed that the activity of KAS $\gamma$-TMT3 promoter was higher than that of Ichihime $\gamma$-TMT3 promoter. In this study, it is also demonstrated that genetic variation in the promoter region of $\gamma$-TMT3 was associated with both $\alpha$-tocopherol content and concentration in soybean seeds. 


\section{Methods}

Plant material and growing conditions

A total of $140 \mathrm{~F}_{2}$ seeds derived from crosses between Ichihime and KAS were used for QTL mapping. The distal portion of each seed was cut off and used for tocopherol concentration analysis. The $\mathrm{F}_{2}$ seeds were grown in commercial potting soil (Katakura Chikkarin Co., Ltd., Japan) in the greenhouse of Hokkaido University, Japan $\left(43^{\circ} 0^{\prime} \mathrm{N}, 141^{\circ} 21^{\prime} \mathrm{E}\right)$ in 2005 . Ten seeds from each plant were collected and bulked for tocopherol concentration analysis. Leaves were harvested from each plant, frozen immediately in liquid nitrogen and stored at $-30^{\circ} \mathrm{C}$ until DNA extraction.

For gene expression and tocopherol quantification analysis in developing seeds, HIF-derived lines were used. An HIF $\left(\mathrm{F}_{5}-24\right)$ was identified as being heterozygous around the $\gamma$-TMT3 locus based on the genotypes of the SSR markers at flanking loci. The plant was selfed to obtain lines that were homozygous for either Ichihime or KAS marker alleles around the $\gamma$-TMT3 locus. Three lines homozygous for the Ichihime alleles (24-10, 24-14, 24-15) and three lines homozygous for the KAS alleles (24-7, 24-18, 24-22) were used for analysis; these sets of lines are referred to as Ichihime lines and KAS lines, respectively. All lines were grown at the Hokkaido University experimental farm in June 2008. Seeds of each plant were sampled at 30 days after flowering (DAF), $40 \mathrm{DAF}$ and $50 \mathrm{DAF}$. The seeds were immediately frozen in liquid nitrogen and stored at $-80^{\circ}$ $C$ until gene expression and tocopherol content analyses.

\section{Extraction and HPLC analysis of tocopherols}

Tocopherols were extracted from mature seeds and analyzed by reverse-phase high performance liquid chromatography (HPLC) following the procedure described by Dwiyanti et al. [18].

For $\mathrm{F}_{2}$ seeds, a distal portion of the seed was cut off with razor blade and cut into bits. Ten $\mathrm{mg}$ of sample was weighed and sonicated in $300 \mu \mathrm{l}$ of $80 \%$ aqueous ethanol for $10 \mathrm{~min}$ at room temperature. Hexane $(600$ $\mu \mathrm{l})$ was added to the sample for extraction. The sample was let sit at $4^{\circ} \mathrm{C}$ before being centrifuged at 13,000 rpm for 5 min using a refrigerated centrifuge (Eppendorf centrifuge 5417R, Eppendorf). The upper (hexane) phase was transferred to an HPLC vial (Waters Corp., Japan). Analysis was performed in an HPLC system (Hitachi LaChrom Elite, Hitachi High-Technologies Corp., Japan) with an Inertsil ODS-3 reverse-phase column (3.0 $\mathrm{mm} \times$ $250 \mathrm{~mm}$, GL Sciences, Japan). Column temperature was maintained at $40^{\circ} \mathrm{C}$ and separation was performed under isocratic condition for $25 \mathrm{~min}$. Solvent A was acetonitrile, solvent $\mathrm{B}$ was methanol, and the ratio of solvent $\mathrm{A}$ to solvent B was 75:25 (v/v). Flow rate was $0.5 \mathrm{ml} / \mathrm{min}$. Tocopherols were detected at the wavelength of $295 \mathrm{~nm}$.

For $\mathrm{F}_{3}$ seeds derived from $\mathrm{F}_{2}$ plants, five seeds from each plant were bulked and ground into fine powder. Seed powder (50 mg) was weighed into a 15-ml test tube. The powder was sonicated in $1 \mathrm{ml}$ of $80 \%$ aqueous ethanol for 15 minutes at room temperature. After incubation at $4^{\circ} \mathrm{C}$ for $30 \mathrm{~min}$, the sample was centrifuged for $10 \mathrm{~min}$ at $2,500 \mathrm{rpm}$ in a Tomy RL-100 centrifuge (Tomy Seiko Co., Japan). The upper phase was transferred to an HPLC vial. Analysis was performed in an HPLC system (Hitachi LaChrom Elite, Hitachi HighTechnologies Corp., Japan) with same column as used for the $\mathrm{F}_{2}$ seed analysis. Column temperature was maintained at $40^{\circ} \mathrm{C}$ and separation was performed under isocratic condition for $25 \mathrm{~min}$. The mobile phase was acetonitrile:methanol at a ratio 90:10 (v/v) ratio. Flow rate was $0.5 \mathrm{ml} / \mathrm{min}$. Tocopherols were detected at the wavelength of $295 \mathrm{~nm}$. Each analysis was performed twice.

Tocopherol extraction and quantification of developing seeds were performed based on a procedure developed previously [29] with several modifications. Twenty mg of freeze-dried seed powder was stirred in $1 \mathrm{ml}$ cold acetone. The sample was sonicated at room temperature for $20 \mathrm{~min}$. After the sonication, the sample was incubated at $4^{\circ} \mathrm{C}$ for $30 \mathrm{~min}$. Centrifugation was performed twice, at 13,000 rpm for $10 \mathrm{~min}$ each time using a refrigerated centrifuge (Eppendorf centrifuge 5417R, Eppendorf). The upper solution was transferred into an HPLC vial. The analysis was performed using a Hitachi LaChrom Elite with a reverse-phase column (Inertsil ODS-3, $4.6 \mathrm{~mm} \times 250 \mathrm{~mm}$ ). The column temperature was maintained at $40^{\circ} \mathrm{C}$. The analysis was performed under isocratic condition, with a mobile phase of ethyl acetate:75\% methanol at a ratio of 50:50 (v/v). Tocopherols were detected by UV light with the detection wavelength set at $295 \mathrm{~nm}$. Each analysis was performed three times.

Tocopherol content in the sample was calculated against the peak area of dl-tocol (Tama Biochemical Co. Ltd. Japan). dl-Tocol was added into the $80 \%$ ethanol or acetone used in the extraction at a concentration of 3 $\mu \mathrm{g} / \mathrm{ml}$.

\section{Genotyping}

Leaves from each $\mathrm{F}_{2}$ plants were sampled and stored at $-30^{\circ} \mathrm{C}$ until DNA extraction. Genomic DNA isolation was performed according to the CTAB method as described by Dwiyanti [18]. About $0.2 \mathrm{~g}$ of leaf tissue ground in liquid nitrogen was added to $700 \mu \mathrm{l}$ of cetyl trimethyl ammonium bromide (CTAB) extraction buffer. After $30 \mathrm{~min}$ incubation at $60^{\circ} \mathrm{C}$, the extract was mixed 
with $700 \mu \mathrm{l}$ of chloroform:isoamyl alcohol $(24: 1 \mathrm{v} / \mathrm{v})$, and centrifuged at $10,000 \mathrm{rpm}$ for $5 \mathrm{~min}$ in a refrigerated centrifuge Tomy MR150 (Tomy Seiko Co., Japan). The aqueous solution was transferred to a $1.5-\mathrm{ml}$ tube, and mixed with $500 \mu \mathrm{l}$ of cold isopropanol for nucleic acid precipitation. Crude nucleic acids were collected by centrifugation at 10,000 rpm for $5 \mathrm{~min}$ in a refrigerated centrifuge Tomy MR150 (Tomy Seiko Co., Japan). The nucleic acid pellet was washed with $150 \mu$ l of $70 \%$ ethanol and the remaining liquid was evaporated. The pellet was then dissolved in TE buffer. RNA was precipitated by lithium chloride as described in [18]. About $20 \mathrm{ng}$ of total DNA was used as the template for PCR analysis.

SSR markers were selected from the soybean consensus linkage map [30] to cover all soybean linkage groups and tested for polymorphism between Ichihime and KAS. Additional SSR markers were developed based on the soybean genomic database Phytozome [20] and soybean SSR database BARCSOYSSR_1.0 [31]. Genotypes of 148 selected SSR markers were determined in $F_{2}$ plants. The DNA band for each marker was amplified by using the PCR procedure described previously [18]. Amplified products were separated on either 3\% Agarose S (Wako Pure Chemical Industries, Ltd), 4\% NuSieve Agarose S (Cambrex Bio Science Rockland, Inc.), or $10 \%$ polyacrylamide gel. The gel was stained with ethidium bromide, and DNA bands were photographed under UV light.

\section{Genetic mapping and QTL analysis}

A linkage map based on the genotypes of 152 SSR markers in $122 \mathrm{~F}_{2}$ plants was constructed using MapManager QTX [32]. Map distances were calculated in centiMorgans (cM) by using the Kosambi function.

QTL analyses for $\alpha$-tocopherol concentration, $\gamma$-tocopherol concentration and $\delta$-tocopherol concentration were carried out in both $F_{2}$ seeds and $F_{2}$ plants. For $F_{2}$ plants, QTL analyses for $\alpha$-tocopherol content and $\gamma$ tocopherol content were also performed. Permutation analysis (1,000 times) was performed to determine the genome-wide minimum significant LOD threshold score. Based on the analysis result, QTLs with LOD score exceeding 2.8 were regarded as effective loci. Initial QTL mapping was performed by using the interval mapping (IM) method provided in MapQTL 5.0 [19]. Markers flanking the QTLs were used as cofactors in QTL mapping by using the MQM method in the same program.

\section{Fine mapping}

$\mathrm{F}_{5}$ plants were generated from $\mathrm{F}_{2}$ plants by using the single-seed-descent method. These $\mathrm{F}_{5}$ plants were planted at the Hokkaido University experimental farm, Japan $\left(43^{\circ} 0^{\prime} \mathrm{N}, 141^{\circ} 21^{\prime} \mathrm{E}\right)$ in June 2007 . Ten seeds from each plant were bulked for tocopherol concentration analysis, and the leaves of each plant were used for DNA genotyping. Tocopherol quantification was performed with the same method used for $F_{3}$ seeds. DNA was extracted from leaves with the CTAB method.

Six SSR markers (Table 4) were developed to identify recombinants in the region containing the QTL. These markers genotypes were determined in $\mathrm{F}_{5}$ plants. The PCR reaction mixture was 20 ng DNA, $1 \mu \mathrm{l}$ of $10 \times$ PCR buffer (TaKaRa), $0.25 \mathrm{mM}$ of dNTP mixture (TaKaRa), $0.2 \mu \mathrm{M}$ forward primer, $0.2 \mu \mathrm{M}$ reverse primer and 0.5 units of Taq DNA polymerase (TaKaRa) in a total volume of $10 \mu \mathrm{l}$. PCR reaction was performed as follows: an initial denaturation step at $95^{\circ} \mathrm{C}$ for $5 \mathrm{~min}$; followed by 35 cycles of $95^{\circ} \mathrm{C}$ for $30 \mathrm{~s}, 58^{\circ} \mathrm{C}$ for $30 \mathrm{~s}$, and $72^{\circ} \mathrm{C}$ for $30 \mathrm{~s}$; followed by a final extension step at $72^{\circ} \mathrm{C}$ for 7 min. PCR products were separated on $10 \%$ acrylamide gels, and bands were visualized under UV illumination.

\section{Phylogenetic analysis and plastid transit peptide prediction}

Amino acid sequences of $\gamma$-TMT1, $\gamma$-TMT2, and $\gamma$ TMT3 were obtained from the Phytozome database [20]. Amino acid sequences of $\gamma$-TMT homologs from cyanobacteria (Synechococcus sp. PCC 7002 [ACA99779.1]), green algae (Chlamydomonas reinhardtii [CA159122.1]), plants (Lotus japonicus [DQ013360.1], Medicago truncatula [AY962639.1], Arabidopsis [AT1G64970], sunflower [DQ229832.1 and DQ229834.1], rapeseed [EU637012.1, EU637013.1, EU637014.1. EU637015.1], maize [AJ634706.1], rice (Oryza sativa L.) [BAD07529.1], wheat (Triticum aestivum L.) [CA177219.2], and Perilla frutescens [AF213481.1]) were obtained from TAIR [33] and NCBI GenBank [34]. The sequences were aligned by the

Table 4 Primers used for fine mapping.

\begin{tabular}{llc}
\hline Primer name & Direction & Nucleotide sequence $\mathbf{( 5}^{\prime}$ to $\left.\mathbf{3}^{\prime}\right)$ \\
\hline KSC138-9 & $\begin{array}{l}\text { Forward } \\
\text { Reverse }\end{array}$ & $\begin{array}{l}\text { GCACAATAAATGGGCCTGA } \\
\text { GCGAGTGTTGGGCTAAGTCT }\end{array}$ \\
\hline KSC138-10 & Forward & CACGAATGTGAATTGATCG \\
& Reverse & CGACCAAGGAGATAAAAACAGA \\
\hline KSC138-17 & Forward & TGGAATTCTGTGCACTTGGTG \\
& Reverse & TAAAGCCGCCTAGCCGATTG \\
\hline KSC138-22 & Forward & TGCAGCAATAATCAATCAAATAGAA \\
& Reverse & TTCAATCAAATTAGCACGTGTATT \\
\hline KSC138-23 & Forward & CGGTCCAGATTTAATTCTTCACTC \\
& Reverse & TTCCGTTTGTCACCCTGCT \\
\hline BARCSOYSSR_09_1388 & Forward & TTGCACTCTCCAAACCAAGA \\
& Reverse & ATGCACTCTGCTCGACACAT \\
\hline BARCSOYSSR_09_1415 & Forward & CACCATCCACTCCAGTTCCT \\
& Reverse & CTCCACGTGTTAGACGGGTT \\
\hline
\end{tabular}


ClustalW function in MEGA 4.0 software [35]. A phylogenetic tree of the proteins was constructed by using the neighbor-joining method in MEGA 4.0 software [35]. A bootstrap (resampling) test was performed 1,000 times to determine the distances between proteins. Plastid transit peptide prediction was performed using ChloroP 1.1 [36].

\section{Gene cloning and sequencing}

Genomic DNA samples from high $\alpha$-tocopherol soybean varieties (KAS, Dobrogeance, and Dobrudza 14 Pancevo) and typical soybean varieties (Ichihime, Toyokomachi, and Williams 82) were isolated by the CTAB method described in the genotyping section. Primer pairs were designed based on $\gamma$-TMT3 (Glyma09g35680.1) genomic information [20]. $\gamma$-TMT3 fragments were amplified by using the following PCR conditions: initial denaturation step at $95^{\circ} \mathrm{C}$ for $5 \mathrm{~min}$; followed by 35 cycles of $95^{\circ} \mathrm{C}$ for $30 \mathrm{~s}$, annealing temperature for $30 \mathrm{~s}, 72^{\circ} \mathrm{C}$ for $1 \mathrm{~min}$; followed by a final extension step at $72^{\circ} \mathrm{C}$ for $7 \mathrm{~min}$. PCR products were separated in 1\% Agarose S gel (Wako Pure Chemical Industries, Ltd). Expected amplification products were excised from the gel, precipitated with ethanol and ligated into the pGEM-T Easy vector (Promega Corp.). Vectors containing DNA fragments were transformed into Escherichia coli strain JM109. After overnight culture, plasmids were isolated by using Wizard SV Plus Minipreps (Promega Corp.). DNA fragments were treated with a Big Dye Terminator Cycle Sequencing ver.3.1 kit (Applied Biosystems) with the following reaction conditions: 30 cycles of $96^{\circ} \mathrm{C}$ for $10 \mathrm{~s}$, $50^{\circ} \mathrm{C}$ for $5 \mathrm{~s}$ and $60^{\circ} \mathrm{C}$ for $2 \mathrm{~min}$. DNA fragments were sequenced by using an ABI PRISM 3130 Genetic Analyzer (Applied Biosystems) and the sequences were aligned using the BioEdit Sequence Alignment Editor [37].

\section{RNA extraction}

Total RNA was extracted from developing seeds or leaves following the lithium chloride precipitation procedure [38] with several modifications. After frozen tissue (about $200 \mathrm{mg}$ ) was ground to a fine powder in liquid nitrogen, $150 \mu \mathrm{l}$ of Tris-saturated phenol $(\mathrm{pH}$ 8.0) and $500 \mu \mathrm{l}$ of extraction buffer $(10 \mathrm{mM}$ Tris- $\mathrm{HCl} \mathrm{pH}$ 7.5, 1 mM EDTA pH 8.0, $100 \mathrm{mM} \mathrm{NaCl}, 1 \%$ SDS) were added to the frozen powder. The mixture was ground thoroughly. Three-hundred $\mu \mathrm{l}$ of chloroform:isoamyl alcohol $(24: 1 \mathrm{v} / \mathrm{v})$ was added to the sample, the solution was vortexed, and the aqueous and organic layers were separated by centrifugation $\left(15,000 \mathrm{rpm}, 10 \mathrm{~min}, 4^{\circ} \mathrm{C}\right)$ in a refrigerated centrifuge (HITACHI Himac CF15RX II, Tokyo, Japan). The aqueous phase was transferred into a 1.5-ml tube. The chloroform:isoamyl alcohol treatment was performed twice. The RNA was precipitated by the addition of 0.3 volumes of $10 \mathrm{M}$ lithium chloride. After being stored at $4^{\circ} \mathrm{C}$ overnight, the solution was centrifuged $\left(15,000 \mathrm{rpm}, 15 \mathrm{~min}, 4^{\circ} \mathrm{C}\right)$. The RNA pellet was dried by leaving the tube opened on ice. The RNA pellet was resuspended in RNase free water.

DNA was removed from the resuspended pellet by DNase I treatment. Ten units of DNase I (TaKaRa) and DNase I buffer was added into the RNA solution. The mixture was incubated at $37^{\circ} \mathrm{C}$ for $30 \mathrm{~min}$. RNA was precipitated again in the presence of $0.3 \mathrm{M}$ sodium acetate and 2.5 volumes of ethanol. The RNA pellet was dried, and again resuspended in RNase free water.

\section{Quantitative RT-PCR analysis}

Each cDNA was synthesized from $1 \mu \mathrm{g}$ of total RNA by using the M-MLV reverse transcriptase system (Invitrogen) with random hexamer primers according to the manufacturer's instructions. After synthesis, one volume of cDNA was diluted with four volumes of nuclease-free water.

The quantitative RT-PCR reaction was conducted in a $20-\mu \mathrm{l}$ volume containing $5 \mu \mathrm{l}$ of cDNA, $12.5 \mathrm{~mol}$ of each primer and $2 \times$ SYBR Premix Ex Taq II (Applied Biosystems). The reaction was performed in a DNA Engine Opticon3 (MJ Research Inc.) under the following conditions: 40 cycles of $95^{\circ} \mathrm{C}$ for $20 \mathrm{~s}, 58^{\circ} \mathrm{C}$ for $20 \mathrm{~s}$ and $72^{\circ} \mathrm{C}$ for $20 \mathrm{~s}$. The specificity of the amplification was verified by melting-curve analysis. The expression levels of the $\gamma$-TMT genes were normalized to the level of 18 rRNA for developing seeds analysis, and to $\beta$-tubulin for leaf analysis. Primers used for each $\gamma$-TMT gene, $18 \mathrm{~S}$ rRNA and $\beta$-tubulin are summarized in Table 5.

\section{Bioinformatic analysis of the promoter sequences}

The upstream $1.3 \mathrm{~kb}$ regions of $\gamma$-TMT3 from Ichihime, Toyokomachi, Williams 82, KAS, Dobrogeance, and Dobrudza 14 Pancevo were analyzed. Regulatory elements in these regions were analyzed using program PLACE [39] and PLANTCARE [40].

Table 5 Primers used for gene expression analysis.

\begin{tabular}{ccc}
\hline Primer name & Direction & Nucleotide sequence $\left(\mathbf{5}^{\prime}\right.$ to $\mathbf{3}^{\prime}$ ) \\
\hline $\boldsymbol{\gamma}$-TMT1 & $\begin{array}{c}\text { Forward } \\
\text { Reverse }\end{array}$ & $\begin{array}{c}\text { CTGGAGGCAGAGTATAGCG } \\
\text { AAACTCCCAGGTCCACCCAAT }\end{array}$ \\
\hline $\boldsymbol{\gamma}$-TMT2 & Forward & GAAGCAAGTTCCAACAGGTCG \\
& Reverse & CGCCAATCATAGGAGATATTGCATATG \\
\hline 18S rRNA & Forward & CAGTGGACTTAAAACCATAAAGGGAGC \\
& Feverse & CCACATACTCTATATCATTCACACGAG \\
\hline \multirow{2}{*}{-tubulin } & Reverse & TGATTAACAGGGACAGTCGG \\
& Forward & GAGAAGAGTATATCATCGTCTTCG \\
\hline & Reverse & GAGCTTGAGTGTTCGGAAAC \\
\hline
\end{tabular}




\section{Generation of transgenic Arabidopsis harboring GUS gene under the control of $\gamma$-TMT3 promoter}

The $1.2 \mathrm{~kb}$ region upstream the transcriptional start site in the $\gamma$-TMT3 promoter was amplified from Ichihime and KAS, cloned into PCR $^{\circledR} 8 / \mathrm{GW} / \mathrm{TOPO}^{\circledR}$ vector (Invitrogen). The plasmids were sequenced. The promoter fragments were inserted into a plant expression vector pMDC100 [41] containing a $\beta$-glucuronidase (GUS) reporter gene [42]. The construct was introduced into Agrobacterium tumefaciens strain EHA105. Arabidopsis thaliana ecotype Columbia plants were transformed with $A$. tumefaciens harboring the expression vector using a floral-dip method [43].

\section{GUS histochemical and activity analyses}

For GUS histochemical assay of transgenic Arabidopsis, leaves from $T_{2}$ plants were soaked with staining solution containing $1 \mathrm{mg} \mathrm{ml}^{-1}$ of 5-bromo-4-chloro-3-indoyl- $\beta$-dglucuronide (X-Gluc) based on protocol described by [44]. The soaked leaves were vacuumed for 10 minutes and incubated overnight at $37^{\circ} \mathrm{C}$. The chlorophylls were removed by a rinse with $99.5 \%$ ethanol after staining treatment.

For GUS activity assay, crude protein was extracted from leaves of $\mathrm{T}_{2}$ plants with $200 \mu \mathrm{l}$ of extraction buffer containing $50 \mathrm{mM}$ of sodium phosphate ( $\mathrm{pH} 7.0)$, $10 \mathrm{mM}$ of EDTA (pH 8.0), $0.1 \%$ of SDS, and $0.1 \%$ of Triton X-100. Sixteen $\mu \mathrm{l}$ of the extract was mixed with $50 \mu \mathrm{l}$ of $1 \mathrm{mM} 4$-methylumbelliferyl- $\beta$-D-glucuronide (4-MUG) and $34 \mu \mathrm{l}$ of extraction buffer, and incubated at $37^{\circ} \mathrm{C}$ for $0 \mathrm{~min}, 30 \mathrm{~min}$, and $60 \mathrm{~min}$. The reactions were stopped by adding $200 \mu \mathrm{l}$ of $0.2 \mathrm{M}$ sodium carbonate. The fluorescence of 4-methylumbelliferone (4MU) derived from the reaction was measured using Wallac ArvoTM 1420 Multilabel Counter (Perkin Elmer). Protein content in the extracts was determined using Quick Start ${ }^{\mathrm{TM}}$ Bradford Protein Assay Kit (BioRad Laboratories). GUS activity was expressed as pmol 4 -MU. $\min ^{-1} \cdot \mathrm{mg}$ protein.

\section{Accession Numbers}

Sequence data from this article can be found in the GenBank/EMBL/DDBJ data libraries under the following accession number: Ichihime $\gamma$-TMT3 promoter (AB617792), KAS $\gamma$-TMT3 promoter (AB617793), Toyokomachi $\gamma$-TMT3 promoter (AB617794), Williams $82 \gamma$ TMT3 promoter (AB617799), KAS $\gamma$-TMT3 coding sequence (AB617795), Ichihime $\gamma$-TMT3 coding sequence (AB617796), KAS $\gamma$-TMT3 genome (AB617797), and Ichihime $\gamma$-TMT3 genome (AB617798).

\section{Acknowledgements}

This work was supported by the Ministry of Education, Culture, Sports, Science and Technology of Japan, Grants-in-Aid for Scientific Research,
19380001. Project for Utilizing Advanced Technologies in Agriculture, Forestry and Fisheries, 18063. We would like to thank Dr. Satoshi Watanabe for helpful advice in developing SSR markers for fine mapping. We would like to thank Ms. A. Shibayama, Ms. K. Ishimoto, and Ms. K. Asano for their technical assistance.

\section{Authors' contributions}

MSD participated in the conception, design, and performance of all experiments. TY was responsible for the fine mapping and gene expression analysis. MS was involved in the analysis for genetic polymorphism. JA was involved in the genetic analysis of the mapping population. KK was responsible for the evaluation of seed contents and participated in experimental conception. All authors contributed to writing of the manuscript. All authors read and approved the final manuscript.

\section{Competing interests}

The authors declare that they have no competing interests.

Received: 12 April 2011 Accepted: 7 November 2011

Published: 7 November 2011

\section{References}

1. Bramley PM, Elmadfa I, Kafatos A, Kelly FJ, Manios Y, Roxborough HE, Schuch W, Sheehy PJA, Wagner K-H: Vitamin E. J Sci Food Agric 2000, 80:913-938.

2. Herbers K: Vitamin production in transgenic plants. J Plant Physiol 2003, 160:821-829

3. Subramaniam S, Slater S, Karberg K, Chen R, Valentin HE, Wong Y-H: Nucleic acid sequences to proteins involved in tocopherol synthesis. International patent application WO 01/79472 2001.

4. Clemente TE, Cahoon EB: Soybean oil: genetic approaches for modification of functionality and total content. Plant Physiol 2009, 151:1030-1040.

5. Hoppe PP, Krennrich G: Bioavailability and potency of natural-source and all-racemic alpha-tocopherol in the human: a dispute. Eur J Nutr 2000, 39:183-193.

6. Van Eenennaam AL, Lincoln $K$, Durrett TP, Valentin HE, Shewmaker CK, Thorne GM, Jiang J, Baszis SR, Levering CK, Aasen ED, Hao M, Stein JC, Norris SR, Last RL: Engineering vitamin E content: from Arabidopsis mutant to soy oil. Plant Cell 2003, 15:3007-3019.

7. Ujiie A, Yamada T, Fujimoto K, Endo Y, Kitamura K: Identification of soybean varieties with high a-tocopherol content. Breed Sci 2005, 55:123-125.

8. Tavva VS, Kim YH, Kagan IA, Dinkins RD, Kim KH, Collins GB: Increased atocopherol content in soybean seed overexpressing the Perilla frutescens y-tocopherol methyltransferase gene. Plant Cell Rep 2007, 26:61-70.

9. Christen S, Woodall AA, Shigenaga MK, Southwell-Keely PT, Duncan MW, Ames BN: $y$-Tocopherol traps mutagenic electrophiles such as NOx and complements a-tocopherol: Physiological implications. Proc Natl Acad Sci USA 1997, 94:3217-3222.

10. Jiang Q, Christen S, Shigenaga MK, Ames BN: gamma-Tocopherol, the major form of vitamin $\mathrm{E}$ in the US diet, deserves more attention. Am J Clin Nutr 2001, 74:714-722.

11. Munné-Bosch S, Alegre L: The function of tocopherols and tocotrienols in plants. CRC CrC Cr Rev Plant Sci 2002, 21:31-57.

12. Velasco L, Perez-Vich B, Fernandez-Martinez JM: Identification and genetic characterization of a safflower mutant with a modified tocopherol profile. Plant Breeding 2005, 124:459-463.

13. Hass CG, Tang S, Leonard S, Traber MG, Miller JF, Knapp SJ: Three nonallelic epistatically interacting methyltransferase mutations produce novel tocopherol (vitamin E) profiles in sunflower. Theor Appl Genet 2006, 113:767-782.

14. Marwede V, Gul MK, Becker HC, Ecke W: Mapping of QTL controlling tocopherol content in winter oilseed rape. Plant Breeding 2005, 124:20-26.

15. Rocheford TR, Wong JC, Egesel CO, Lambert RJ: Enhancement of vitamin E levels in corn. J Am Coll Nutr 2002, 21:191S-198S.

16. Gilliland LU, Magallanes-Lundback M, Hemming C, Supplee A, Koornneef M, Bentsink L, DellaPenna D: Genetic basis for natural variation in seed vitamin E levels in Arabidopsis thaliana. Proc Natl Acad Sci USA 2006, 103:18834-18841. 
17. Li H, Liu H, Han Y, Wu X, Teng W, Liu G, Li W: Identification of QTL underlying vitamin $\mathrm{E}$ contents in soybean seed among multiple environments. Theor Appl Genet 2010, 120:1405-1413.

18. Dwiyanti MS, Ujiie A, Thuy LTB, Yamada T, Kitamura K: Genetic analysis of high a-tocopherol content in soybean seeds. Breed Sci 2007, 57:23-28.

19. Van Ooijen JW: MapQTL ${ }^{\bullet}$, Software for the mapping of quantitative trait loci in experimental populations.Edited by: Kyazma BV. Wageningen, The Netherlands; 2004:.

20. Phytozome. [http://www.phytozome.net/soybean.php].

21. Shintani D, DellaPenna D: Elevating the vitamin E content of plants through metabolic engineering. Science 1998, 282:2098-2100.

22. Sakata-Takatani K, Matsuo N, Sumiyoshi H, Tsuda T, Yoshioka H: Identification of a functional CBF-binding CCAAT-like motif in the core promoter of the mouse pro-alpha $1(\mathrm{~V})$ collagen gene (Col5a1). Matrix Biol 2004, 23:87-99.

23. Himes $J L$, Xanthopoulos KG: Biological Role of the CCAAT/Enhancerbinding Protein Family of Transcription Factors. J Biol Chem 1998, 273:28545-28548.

24. Fornalé S, Sonbol FM, Maes T, Capellades M, Puigdomènech P, Rigau J, Caparrós-Ruiz D: Down-regulation of the maize and Arabidopsis thaliana caffeic acid O-methyl-transferase genes by two new maize R2R3-MYB transcription factors. Plant Mol Biol 2006, 62:809-823.

25. Tuinstra MR, Ejeta G, Goldsbrough : Heterogeneous inbred family (HIF) analysis: a method for developing near-isogenic lines that differ at quantitative trait loci. Theor Appl Genet 1997, 95:1005-1011.

26. Liebault M, Thibivilliers S, Bilgin DD, Radwan O, Benitez M, Clough SJ, Stacey G: Identification of four soybean reference genes for gene expression normalization. The Plant Genome 2008, 1:44-54.

27. Cheng Z, Sattler S, Maeda H, Sakuragi Y, Bryant DA, DellaPenna D: Highly divergent methyltransferases catalyze a conserved reaction in tocopherol and plastoquinone synthesis in cyanobacteria and photosynthetic eukaryotes. Plant Cell 2003, 15:2343-2356.

28. Soll J, Schultz G, Joyard J, Douce R, Block MA: Localization and synthesis of prenylquinones in isolated outer and inner envelope membranes from spinach chloroplasts. Arch Biochem Biophys 1985, 238:290-299.

29. Wang S, Kanamaru K, Li W, Abe J, Yamada T, Kitamura K: Simultaneous accumulation of high contents of a-tocopherol and lutein is possible in seeds of soybean (Glycine max (L.) Merr.). Breed Sci 2007, 57:297-304.

30. Song QJ, Marek LF, Shoemaker RC, Lark KG, Concibido VC, Delannay X, Specht JE, Cregan PB: A new integrated genetic linkage map of the soybean. Theor Appl Genet 2004, 109:122-128.

31. Song QJ, Jia GF, Zhu YL, Grant D, Nelson RT, Hwang EY, Hyten DL, Cregan PB: Abundance of SSR Motifs and Development of Candidate Polymorphic SSR Markers (BARCSOYSSR_1.0) in Soybean. Crop Sci 2010, 50:1950-1960.

32. Manly KF, Cudmore RH Jr, Meer JM: Map Manager QTX, cross-platform software for genetic mapping. Mamm Genome 2001, 12:930-932.

33. The Arabidopsis Information Resource (TAIR). [http://www.arabidopsis.org/ index.jsp].

34. National Center for Biotechnology Information. [http://www.ncbi.nih.gov].

35. Tamura K, Dudley J, Nei M, Kumar S: MEGA4: Molecular Evolutionary Genetics Analysis (MEGA) software version 4.0. Mol Biol Evol 2007, 24:1596-1599.

36. Emanuelsson $\mathrm{O}$, Nielsen $\mathrm{H}$, von Heijne $\mathrm{G}$ : ChloroP, a neural network-based method for predicting chloroplast transit peptides and their cleavage sites. Protein Sci 1999, 8:978-984.

37. Hall TA: BioEdit: a user-friendly biological sequence alignment editor and analysis program for Windows 95/98/NT. Nucleic Acids Symp Ser 1999, 41:95-98.

38. Napoli C, Lemieux C, Jorgensen R: Introduction of a chimeric chalcone synthase gene into petunia results in reversible co-suppression of homologous genes in trans. The Plant Cell 1990, 2:279-289.

39. PLACE. [http://www.dna.affrc.go.jp/PLACE/].

40. PLANTCARE. [http://bioinformatics.psb.ugent.be/webtools/plantcare/html/].

41. Curtis MD, Grossniklaus U: A gateway cloning vector set for highthroughput functional analysis of genes in planta. Plant Physiol 2003, 133:462-469.

42. Ohta S, Mita S, Hattori T, Nakamura K: Construction and expression in tobacco of a $\beta$-glucuronidase (GUS) reporter gene containing an intron within the coding sequence. Plant Cell Physiol 1990, 31:805-813.
43. Clough SJ, Bent AF: Floral dip: a simplified method for Agrobacteriummediated transformation of Arabidopsis thaliana. Plant J 1998, 16:735-743.

44. Jefferson RA, Kavanagh TA, Bevan MW: GUS fusions: beta-glucuronidase as a sensitive and versatile gene fusion marker in higher plants. EMBO J 1987, 6:3901-3907.

doi:10.1186/1471-2229-11-152

Cite this article as: Dwiyanti et al:: Genetic variation of $\gamma$-tocopherol methyltransferase gene contributes to elevated $\alpha$-tocopherol content in soybean seeds. BMC Plant Biology 2011 11:152.

\section{Submit your next manuscript to BioMed Central and take full advantage of:}

- Convenient online submission

- Thorough peer review

- No space constraints or color figure charges

- Immediate publication on acceptance

- Inclusion in PubMed, CAS, Scopus and Google Scholar

- Research which is freely available for redistribution

Submit your manuscript at www.biomedcentral.com/submit
C Biomed Central 